\title{
El Niño/Southern Oscillation inhibited by submesoscale ocean eddies
}

\author{
Shengpeng Wang ${ }^{1,2}$, Zhao Jing ${ }^{1,2,3} \llbracket$, Lixin Wu ${ }^{1,2}$, Wenju Cai ${ }^{1,2,4}$, Ping Chang ${ }^{3,5,6}$, Hong Wang ${ }^{1,2,3}$, \\ Tao Geng (1) 1,2, Gohkan Danabasoglu ${ }^{3,7}$, Zhaohui Chen ${ }^{10}{ }^{1,2}$, Xiaohui Ma ${ }^{1,2,3}$, Bolan Gan ${ }^{1,2}$ and \\ Haiyuan Yang ${ }^{1,2}$
}

The EI Niño/Southern Oscillation is characterized by irregular warm (El Niño) and cold (La Niña) events in the tropical Pacific Ocean, which have substantial global environmental and socioeconomic impacts. These events are generally attributed to the instability of basin-scale air-sea interactions in the equatorial Pacific. However, the role of sub-basin-scale processes in the EI Niño/Southern Oscillation life cycle remains unknown due to the scarcity of observations and coarse resolution of climate models. Here, using a long-term high-resolution global climate simulation, we find that equatorial ocean eddies with horizontal wavelengths less than several hundred kilometres substantially inhibit the growth of La Niña and El Niño events. These submesoscale eddies are regulated by the intensity of Pacific cold-tongue temperature fronts. The eddies generate an anomalous surface cooling tendency during El Niño by inducing a reduced upward heat flux from the subsurface to the surface in the central-eastern equatorial Pacific; the opposite occurs during La Niña. This dampening effect is missing in the majority of state-of-the-art climate models. Our findings identify a pathway to resolve the long-standing overestimation of El Niño and La Niña amplitudes in climate simulations.

A $s$ the most consequential mode of climate variability on our planet, the El Niño/Southern Oscillation (ENSO) $)^{1,2}$ triggers a cascade of adverse impacts on ecosystems, agriculture and severe weather events around the world ${ }^{3-8}$. For example, during El Niño, atmospheric convection over the western Pacific shifts eastwards ${ }^{9}$, and the associated reorganization of atmospheric circulation causes droughts and wildfires in the western Pacific but floods in the eastern Pacific regions. During La Niña, these impacts, although not exactly symmetric, are generally opposite. Understanding the ENSO's dynamics is thus of broad scientific and socioeconomic interest.

ENSO is thought of as a basin-scale coupled ocean-atmosphere phenomenon arising from the instability of the climatological background state, facilitated by positive feedback between trade-wind intensity and zonal contrasts in sea surface temperature (SST), referred to as Bjerknes feedback ${ }^{10-14}$. It is also controlled by negative feedback and damping effects that limit its growth rate and ultimate magnitude and enable its transition from, for example, an El Niño to a neutral or La Niña condition ${ }^{15-18}$. In the classical ENSO theories, only the basin-scale ocean dynamics that involve the equatorial circulation, cold tongue and thermocline structure balance the positive/negative feedback and damping effects ${ }^{19,20}$.

However, limited observations and high-resolution simulations have revealed a wide spectrum of variability in the equatorial Pacific Ocean ${ }^{21-23}$. Recent studies have provided some insights into the effects of this sub-basin-scale ocean variability on ENSO. For example, equatorial mesoscale eddies, represented mainly by tropical instability waves (TIWs) and associated tropical instability vortices (TIVs) with horizontal wavelengths lying between 600 and $1,600 \mathrm{~km}$ (ref. ${ }^{24}$ ), hinder ENSO growth through a lateral heat flux $^{25-27}$. By contrast, microscale turbulent mixing induced by shear instability 28,29 enhances ENSO amplitude through regulating heat exchange between the subsurface and surface layers ${ }^{28,30,31}$.

A substantial portion of equatorial ocean variability resides between the mesoscale and microscale, manifested in the form of fronts, filaments and coherent vortices that have horizontal wavelengths typically ranging from tens to hundreds of kilometres (submesoscale eddies) ${ }^{22,23}$ (Extended Data Fig. 1). These submesoscale eddies are characterized by strong horizontal SST gradients and vertical velocity, leaving imprints on the surface chlorophyll field (Extended Data Fig. 2). However, the impact of these submesoscale eddies on ENSO remains entirely unexplored and overlooked, probably because they are beyond the resolution capacity of existing observation systems and most state-of-the-art coupled global climate models (CGCMs). In this article, we show an important role of submesoscale eddies in inhibiting ENSO growth and elucidate its underlying dynamics using an unprecedented long-term high-resolution CGCM simulation.

\section{Modelling ENSO at high resolution}

The global climate simulation used in this study is based on the Community Earth System Model (CESM) that has an oceanic resolution of $0.1^{\circ}$ and is completed at the International Laboratory for High-Resolution Earth System Prediction (iHESP) ${ }^{32}$ (see CESMiHESP simulation in Methods). It consists of a $250 \mathrm{yr}$ historical and future transient climate (HF-TNST) run for 1850-2100. Outputs of

'Frontiers Science Center for Deep Ocean Multispheres and Earth System and Key Laboratory of Physical Oceanography, Ocean University of China, Qingdao, China. ${ }^{2}$ Pilot National Laboratory for Marine Science and Technology (Qingdao), Qingdao, China. ${ }^{3}$ International Laboratory for HighResolution Earth System Prediction, Texas A\&M University, College Station, TX, USA. ${ }^{4}$ Center for Southern Hemisphere Oceans Research (CSHOR), CSIRO Oceans and Atmosphere, Hobart, Tasmania, Australia. ${ }^{5}$ Department of Oceanography, Texas A\&M University, College Station, TX, USA. ${ }^{6}$ Department of Atmospheric Sciences, Texas A\&M University, College Station, TX, USA. ${ }^{7}$ National Center for Atmospheric Research, Boulder, CO, USA. 凶e-mail: jingzhao@ouc.edu.cn 


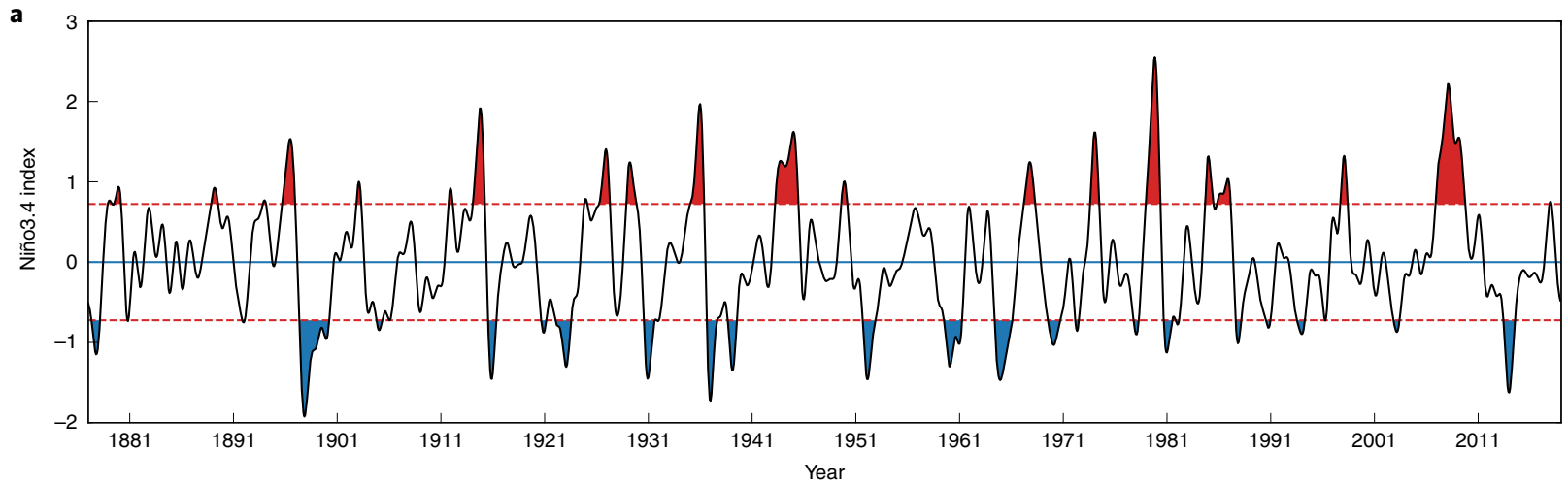

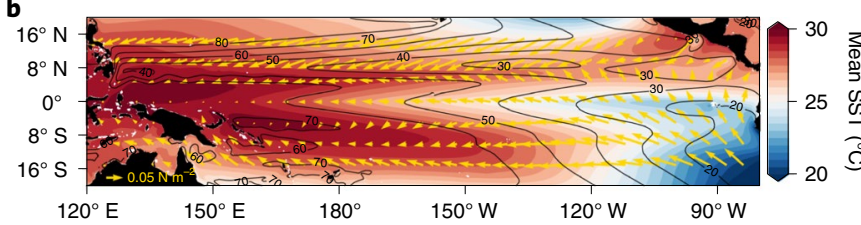
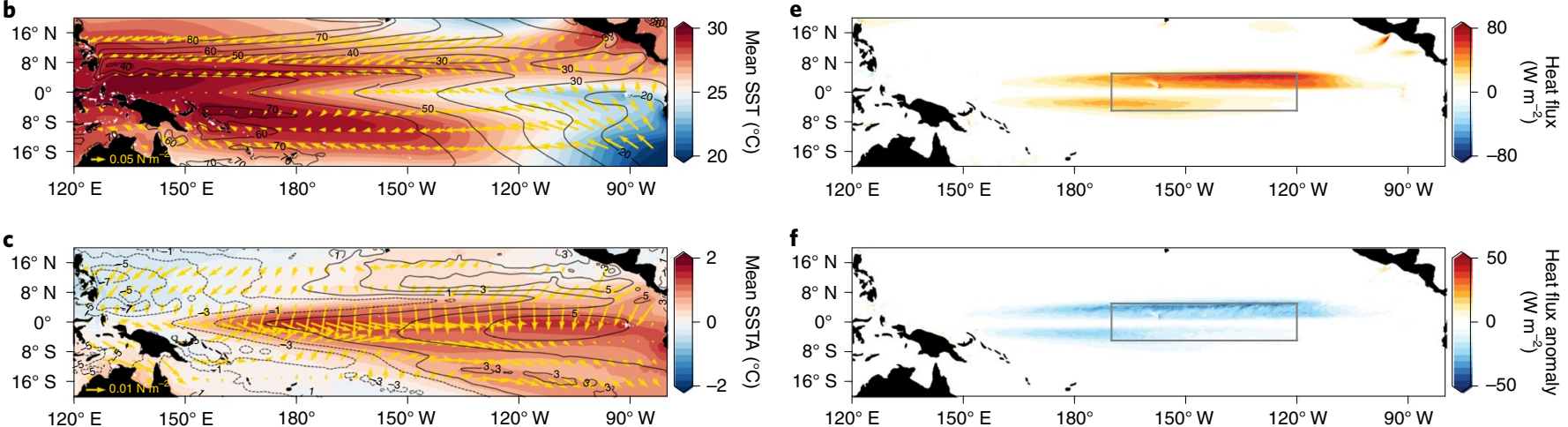

f
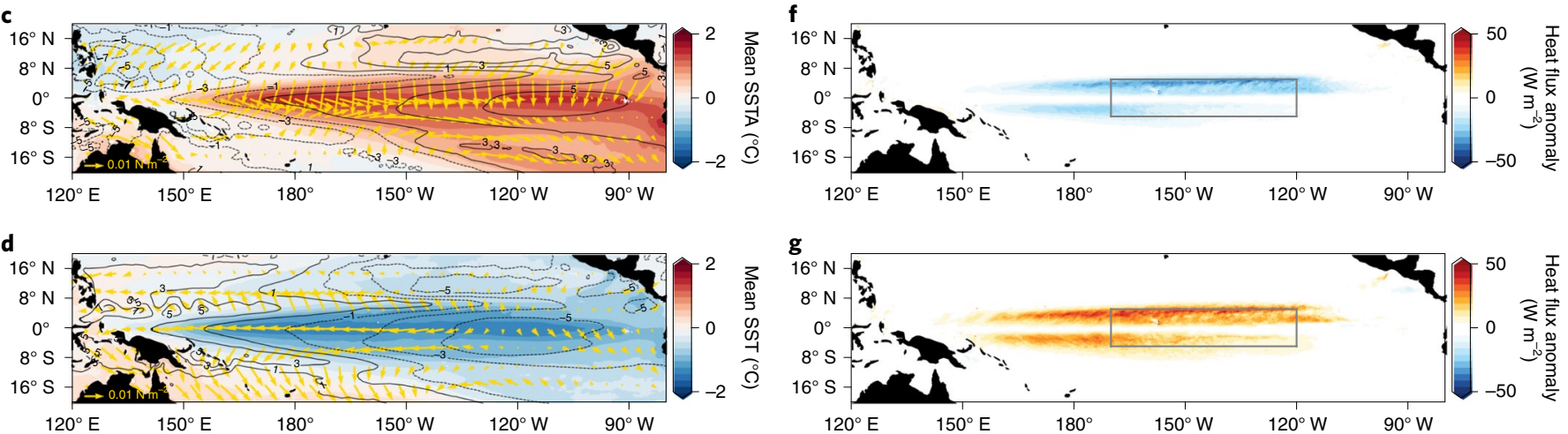

Fig. 1 Simulated ENSO and vertical submesoscale eddy heat flux. a, Linearly detrended Niño3.4 index time series computed from the CESM-iHESP simulation with the peak El Niño (La Niña) events filled in red (blue). b-d, Climatological mean SST ( ${ }^{\circ} \mathrm{C}$, shading), sea surface height (cm, contours) and wind stress ( $\mathrm{N} \mathrm{m}^{-2}$, vectors) (b) and the composite of their anomalies at the peak El Niño (c) and La Niña events (d). e-g, Same as b-d but for vertical submesoscale eddy heat flux $\left(\mathrm{W} \mathrm{m}^{-2}\right)$ at $50 \mathrm{~m}$ and its anomalies. The peak El Niño (La Niña) event is defined as the period when the detrended Niño3.4 index is higher (lower) than its one (minus one) standard deviation. The boxes in $\mathbf{e}-\mathbf{g}$ encompass the Niño3.4 region.

the simulation between 1878 and 2019 are used in the following analysis, containing 18 El Niño and 20 La Niña events in total (Fig. 1a).

The simulated climatological mean SST and its composite anomalies during all the peak El Niño and La Niña events are reasonably realistic (Fig. 1b-d). During the peak El Niño events, the warm pool expands eastwards to the eastern equatorial Pacific Ocean, accompanied by weakened lower-tropospheric equatorial trade winds and a flattened west-to-east tilt of the sea surface. The oceanic and atmospheric responses are generally reversed for the peak La Niña events. These features are qualitatively consistent with those derived from reanalysis products, despite some noticeable quantitative differences (Extended Data Fig. 3; see Reanalysis and observation products in Methods).

We compare essential components of the Bjerknes feedback loop $^{33,34}$ (Extended Data Fig. 4) in the CESM-iHESP simulation with those in the reanalysis products and state-of-the-art coarse-resolution CGCMs (Extended Data Table 1) participating in the Coupled Model Intercomparison Project Phase 6 (CMIP6) ${ }^{35}$. In terms of the SST-zonal wind stress and thermocline-SST couplings, the CESM-iHESP generally outperforms the coarse-resolution CGCMs. As to the zonal wind stress-thermocline coupling, a dominant process influencing model ENSO amplitude (Extended Data Table 2), the intensity in the CESM-iHESP simulation is comparable to that in the reanalysis products and is close to the ensemble average of the coarse-resolution CGCMs. These comparisons lend support to the reliability of the CESM-iHESP in simulating basic ENSO dynamics.

Crucially, submesoscale eddies induce a pronounced climatological heat flux from the subsurface to the surface ocean, particularly along the northern and southern edges of the cold tongue, with its intensity weakened and strengthened during El Niño and La Niña, respectively (Fig. 1e-g). In the following, we show that the effect of this vertical submesoscale eddy heat flux inhibits ENSO growth.

\section{Submesoscale eddies inhibit ENSO growth}

We perform an SST budget analysis for the Niño3.4 region $\left(5^{\circ} \mathrm{S}-5^{\circ} \mathrm{N}\right.$, $\left.170^{\circ} \mathrm{W}-120^{\circ} \mathrm{W}\right)$ using diagnostic outputs from the CESM-iHESP simulation (see SST budget in Methods) to compare the effects of different ocean processes on ENSO, such as basin-scale circulations, mesoscale eddies, submesoscale eddies and microscale turbulent mixing. Following previous studies ${ }^{36,37}$, vertical mean temperature in the upper $50 \mathrm{~m}$ layer is used as a proxy for SST. The climatological mean SST budget reveals a delicate balance between heat sources and sinks in the Niño3.4 region (Fig. 2a). Heat is supplied mainly via ocean heat uptake from the atmosphere $\left(Q_{\text {shf }}\right)$ and an upward eddy heat flux at the layer base $\left(Q_{\text {eddyv }}\right)$. The former and latter 


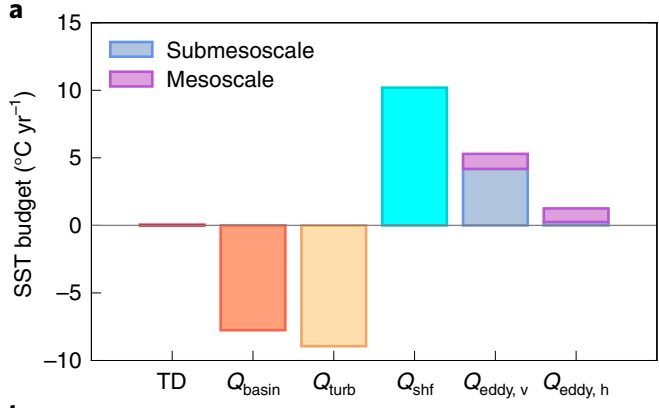

b
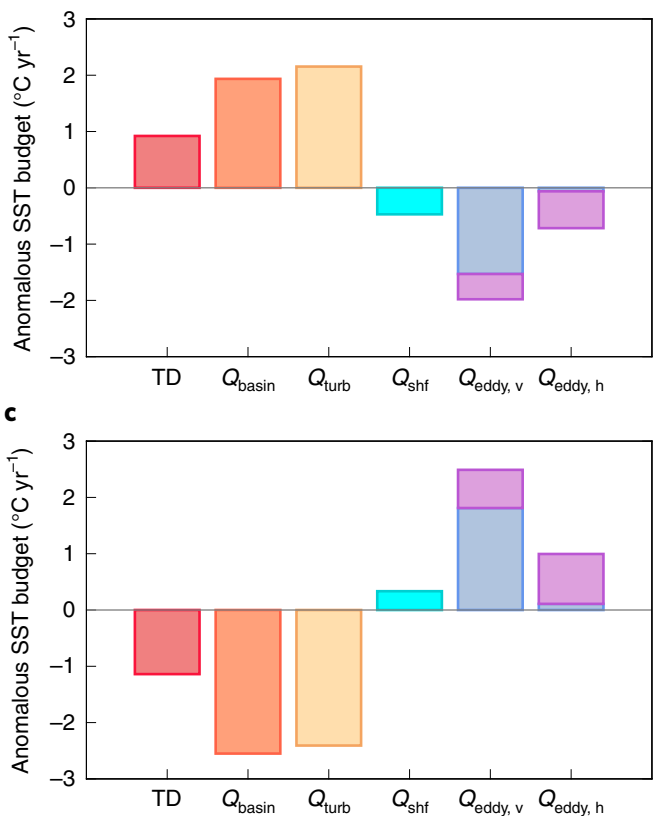
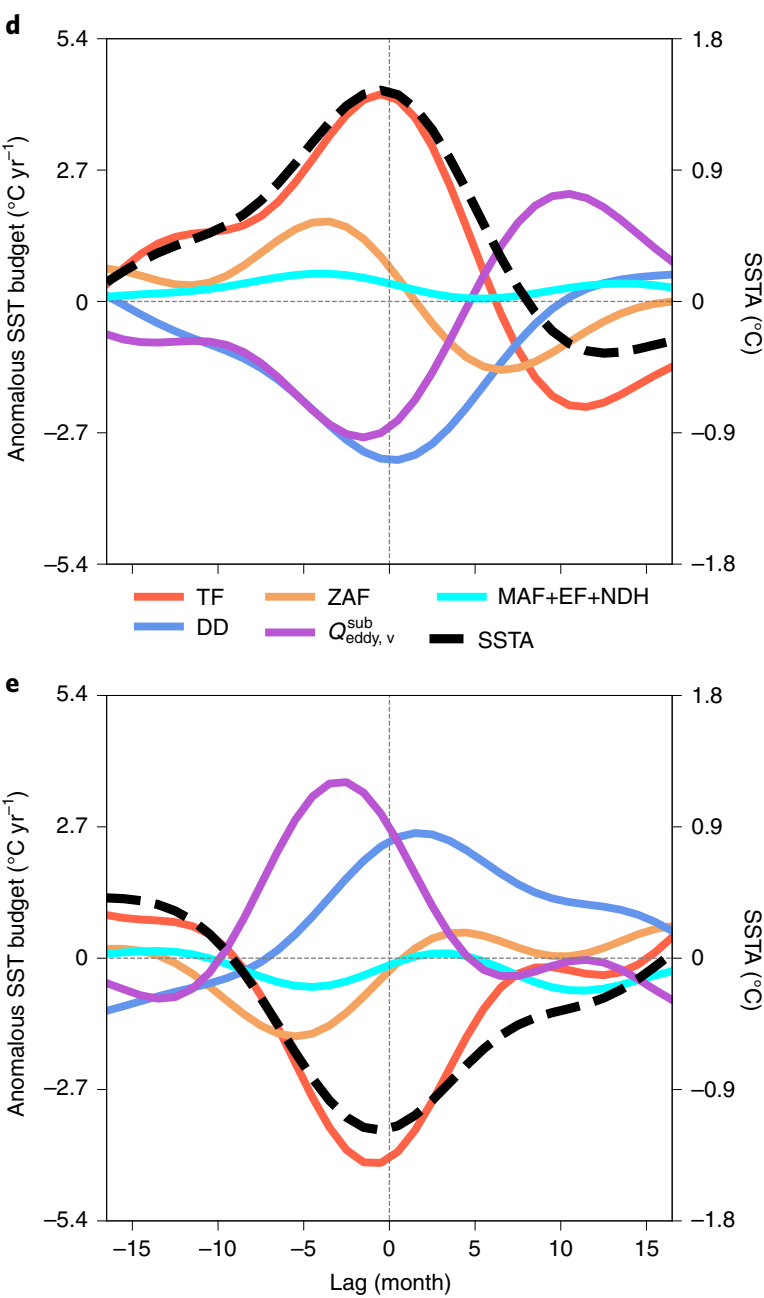

Fig. 2 | Effect of submesoscale eddies on Niño3.4 SST variability. $\mathbf{a}$, The climatological mean SST budget with TD representing the SST tendency, $Q_{\text {basin }}$ the heat-flux convergence of the basin-scale circulations, $Q_{\text {turb }}$ the parameterized microscale turbulent mixing, $Q_{\text {shf }}$ the ocean heat uptake from the atmosphere, $Q_{\text {eddy, }}$ the vertical eddy heat flux at $50 \mathrm{~m}$ (positive into the upper ocean) and $Q_{\text {eddy, }}$ the horizontal eddy heat-flux convergence. $\mathbf{b}, \mathbf{c}$, Same as $\mathbf{a}$ but for the composite anomalous SST budget averaged over the developing phase of all El Niño (b) and La Niña (c) events. $\mathbf{d}$, Decomposition of the anomalous $Q_{\text {basin }}$ during El Niño events into the thermocline feedback (TF), zonal advection feedback (ZAF) and dynamical damping (DD) and the sum of meridional advection feedback (MAF), Ekman feedback (EF) and nonlinear dynamical heating (NDH). All the terms are first expressed as a function of time centred at the peak of SSTA (black dashed) for each El Niño event and then averaged over all the El Niño events. Negative (positive) lag months represent El Niño developing (decaying) phase before (after) the peak of SSTA. e, Same as d, but for La Niña events. The EF, MAF and NDH are individually displayed in Extended Data Fig. 6.

contribute to a warming tendency of $10.2^{\circ} \mathrm{Cyr}^{-1}$ and $5.3^{\circ} \mathrm{Cyr}^{-1}$, respectively. Horizontal eddy heat-flux convergence $\left(Q_{\text {eddy,h }}\right)$ plays a minor role, warming the surface layer at a rate of $1.3^{\circ} \mathrm{Cyr}^{-1}$.

Cross-spectral analysis (Extended Data Fig. 5) indicates that submesoscale eddies $\left(Q_{\text {eddy,v }}^{\text {sub }}\right)$ contribute to a warming tendency of $4.2^{\circ} \mathrm{Cyr}^{-1}$, or about $80 \%$ of $Q_{\text {eddy, }}$ (see Separating effects from mesoscale and submesoscale eddies in Methods), whereas the contribution from mesoscale eddies $\left(Q_{\text {eddy, }}^{\text {meso }}\right)$ is only $1.1^{\circ} \mathrm{Cyr}^{-1}$ (Fig. 2a). By contrast, the values of $Q_{\text {eddy, }}$ contributed by mesoscale $\left(Q_{\text {eddy,h }}^{\text {meso }}\right)$ and submesoscale $\left(Q_{\text {eddy,h }}^{\text {sub }}\right)$ eddies are $1.0^{\circ} \mathrm{Cyr}^{-1}$ and $0.3^{\circ} \mathrm{Cyr}^{-1}$, respectively. Therefore, submesoscale eddies serve as a key heat supplier to the surface Niño3.4 region by transporting heat from the subsurface to the surface ocean. The heat provided by $Q_{\text {shf }}, Q_{\text {eddy, }}$ and $Q_{\text {eddy, }}$ is balanced by the cooling effects due to the heat-flux divergence of the basin-scale circulations $\left(Q_{\text {basin }},-7.8^{\circ} \mathrm{Cyr}^{-1}\right)$ and parameterized microscale turbulent mixing $\left(Q_{\text {turb }},-8.9^{\circ} \mathrm{Cyr}^{-1}\right)$. The resultant temperature tendency is two orders of magnitude smaller than each individual heating or cooling term.
During the El Niño developing phase, defined as the period from the phase transition to the peak, the temperature tendency anomaly is $0.9^{\circ} \mathrm{Cyr}^{-1}$ and becomes one of the leading terms in the SST budget (Fig. 2b). The magnitudes of $Q_{\text {basin }}$ and $Q_{\text {turb }}$ are reduced by $25 \%$ (anomaly of $2.0^{\circ} \mathrm{Cyr}^{-1}$ ) and $24 \%$ (anomaly of $2.1^{\circ} \mathrm{Cyr}^{-1}$ ), respectively. Their combined effect would result in an anomalous temperature tendency more than four times the actual value. This discrepancy is largely compensated by the weakened $Q_{\mathrm{eddy}, \mathrm{v}}^{\mathrm{sub}}$ contributing to a temperature tendency anomaly of $-1.6^{\circ} \mathrm{Cyr}^{-1}$, whereas individual changes in $Q_{\text {eddy,v }}^{\text {meso }}\left(-0.4^{\circ} \mathrm{Cyr}^{-1}\right), Q_{\text {eddy,h }}^{\text {meso }}\left(-0.6^{\circ} \mathrm{Cyr}^{-1}\right)$, $Q_{\text {eddy,h }}^{\text {sub }}\left(-0.1^{\circ} \mathrm{Cyr}^{-1}\right)$ and $Q_{\text {shf }}\left(-0.5^{\circ} \mathrm{Cyr}^{-1}\right)$ make a secondary contribution.

The situation is qualitatively similar for the La Niña developing phase except that all terms are sign-reversed (Fig. 2c). In either El Niño or La Niña, the damping effect on SST anomaly (SSTA) due to submesoscale eddies is about $80 \%$ of the growth effect from the basin-scale circulations. Therefore, by altering the vertical heat exchange between the subsurface and surface ocean, submesoscale 

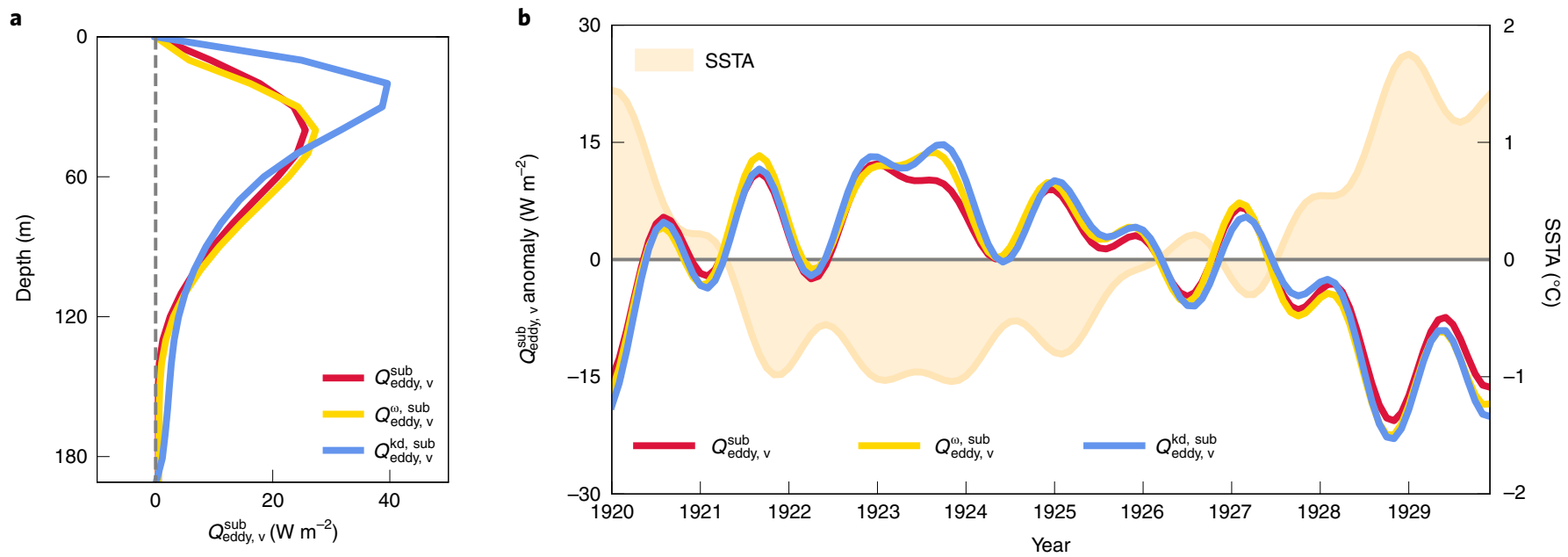

Fig. 3 | Generation mechanisms of vertical submesoscale eddy heat flux. a, Vertical profiles of time-mean vertical submesoscale eddy heat flux $Q_{e d d y, v}^{\text {sub }}$ (red solid) averaged over the Niño3.4 region, reconstructed from the PE omega equation $Q_{e d d y, v}^{\omega, \text { sub }}$ (gold solid) and the component of $Q_{e d d y, v}^{\omega, \text { sub }}$ contributed by the mixed-layer instability and frontogenesis $Q_{e d d y, v}^{\mathrm{kd}, \text { sub }}$ during model years 1920-1929. b. Time series of $Q_{e d d y, v^{\prime}}^{\text {sub }} Q_{e d d y, v}^{\omega, \text { sub }}$ and $Q_{e d d y, v}^{\text {kd, sub }}$ anomalies at $50 \mathrm{~m}$ and SSTA averaged over the Niño3.4 region. All the time series shown in $\mathbf{b}$ are referenced to their climatological seasonal cycles and low-pass filtered with a cut-off period of 12 months.

eddies play an important role in inhibiting the growth of SSTA during El Niño and La Niña.

To further evaluate the role of submesoscale eddies in inhibiting ENSO growth, we compare the influence of $Q_{\text {eddy,v }}^{\text {sub }}$ on evolution of SSTA with those of the basin-scale feedbacks and damping mechanisms in the classical ENSO theory (see Decomposing $Q_{\text {basin }}$ into different feedbacks and damping mechanisms in Methods). These feedbacks and damping mechanisms reinforce or offset each other, with their balance manifested in $Q_{\text {basin }}$ (refs. ${ }^{20,38,39}$ ). Decomposition of $Q_{\text {basin }}$ into different components (Fig. 2d,e and Extended Data Fig. 6) shows results consistent with the previous studies ${ }^{20,38,39}$. For example, the thermocline and zonal advection feedbacks contribute dominantly to the growth of El Niño/La Niña events as well as their phase transition; the dynamical damping is opposite in phase to SSTA, limiting the ENSO amplitude; and the other processes, including the meridional advection feedback, Ekman feedback and nonlinear dynamical heating, play a secondary role. Similar to the dynamical damping, the anomaly of $Q_{\text {eddy,v }}^{\text {sub }}$ is also negatively correlated with the SSTA. In particular, its magnitude is comparable to that of the dynamical damping (Fig. 2d,e), reinforcing the importance of submesoscale eddies in inhibiting ENSO growth.

Finally, there is asymmetry of the anomalies of $Q_{\mathrm{eddy}, \mathrm{v}}^{\mathrm{sub}}$ between $\mathrm{El}$ Niño and La Niña events (Fig. 2b,c). During the El Niño developing phase, the anomaly of $Q_{\mathrm{eddy}, \mathrm{v}}^{\mathrm{sub}}$ induces a cooling rate of $1.6^{\circ} \mathrm{Cyr}^{-1}$, whereas during the La Niña developing phase, the warming rate contributed by the anomaly of $Q_{e d d y, v}^{\text {sub }}$ is $1.8^{\circ} \mathrm{C} \mathrm{yr}^{-1}$. This asymmetric damping effect by submesoscale eddies may contribute to an ENSO asymmetry in the CESM-iHESP simulation (Fig. 2d,e). Nevertheless, given that the asymmetry is controlled by complicated dynamics $^{40}$, the role of submesoscale eddies in generating ENSO asymmetry remains awaiting in-depth analysis.

\section{Frontal intensity governs impact of submesoscale eddies}

To shed light on the underlying dynamics whereby $Q_{\text {eddy,v }}^{\text {sub }}$ damps ENSO, we perform a diagnostic analysis for $Q_{e d d y, v}^{\text {sub }}$ by constructing an omega equation under the primitive equation (PE) framework $^{41}$ (see Decomposing vertical submesoscale eddy heat flux into different ocean dynamics in Methods). The PE omega equation decomposes vertical submesoscale eddy velocity and $Q_{\text {eddy,v }}^{\text {sub }}$ into components driven by different dynamics. However, solving the PE omega equation requires all the individual terms in the momentum, temperature and salinity governing equations. Outputting these terms with a sufficiently high temporal resolution to resolve submesoscale eddies is formidable for the entire simulation period. As a trade-off between the temporal resolution and coverage, daily averaged values were saved for ten years. Figure 3 and Extended Data Fig. 7 compare $Q_{e d d y, v}^{\text {sub }}$ with that computed from the solution of PE omega equation $\left(Q_{\text {eddy,v }}^{\omega, \text { sub }}\right)$. The time-mean vertical profiles of $Q_{\text {eddy,v }}^{\omega, \text { sub }}$ and $Q_{\text {eddy,v }}^{\text {sub }}$ averaged over the Niño3.4 region agree reasonably well, with their peak values differing by only $5 \%$. The temporal variations of $Q_{\text {eddy,v }}^{\omega, \text { sub }}$ and $Q_{\text {eddy,v }}^{\text {sub }}$ at $50 \mathrm{~m}$ averaged over the Niño3.4 region are also highly correlated, with a correlation coefficient of 0.98 statistically significant above the $99 \%$ confidence level. This tight correlation provides strong justification that the $\mathrm{PE}$ omega equation is a reliable diagnostic tool for $Q_{\text {eddy,v }}^{\text {sub }}$.

Decomposition of the $Q_{\text {eddy,v }}^{\text {esub }}$ into different dynamical components reveals that $Q_{\text {eddy,v }}^{\omega, \text { sub }}$ in the upper $100 \mathrm{~m}$ of the Niño3.4 region is ascribed mainly to conversion from eddy available potential energy (EAPE) into eddy kinetic energy (EKE) through the mixed-layer instability and frontogenesis ${ }^{42,43}$ (Fig. 3 and Extended Data Fig. 7). The vertical submesoscale eddy heat flux induced by such effect alone $\left(Q_{\text {eddy,v }}^{\mathrm{kd}, \mathrm{v} u b}\right)$ accounts mostly for the time-mean $Q_{\mathrm{eddy,v}}^{\omega, \text { sub }}$ at $50 \mathrm{~m}$ and dominates its temporal variability at interannual scales. The mixed-layer instability and frontogenesis work most efficiently in the frontal region associated with the large $\mathrm{EAPE}^{44}$. Indeed, the spatial distribution of time-mean $Q_{e d d y, v}^{\text {sub }}$ is consistent with that of the squared horizontal SST gradient magnitude (Fig. 1e and Extended Data Fig. 8). In particular, it exhibits a pronounced enhancement along the meridional edges of the cold tongue where stirring by TIWs/TIVs generates large horizontal SST gradients. During El Niño, the weakened cold-tongue frontal intensity and TIW/TIVs result in reduced horizontal SST gradients, suppressing $Q_{\text {eddy,v }}^{\text {sub }}$ (Fig. $1 \mathrm{f}$ and Extended Data Fig. 8a,c). The opposite is true during La Niña (Fig. $1 \mathrm{~g}$ and Extended Data Fig. 8b,d). The difference in horizontal SST gradients explains the difference of $Q_{e d d y, v}^{\text {sub }}$ between El Niño and La Niña events.

\section{Implication for ENSO modelling}

It is a long-standing issue that most CGCMs simulate an overly large ENSO amplitude ${ }^{34,45,46}$. However, submesoscale eddies and their associated vertical heat flux are not resolved in the majority of CGCMs due to their coarse ocean model resolution. Therefore, 

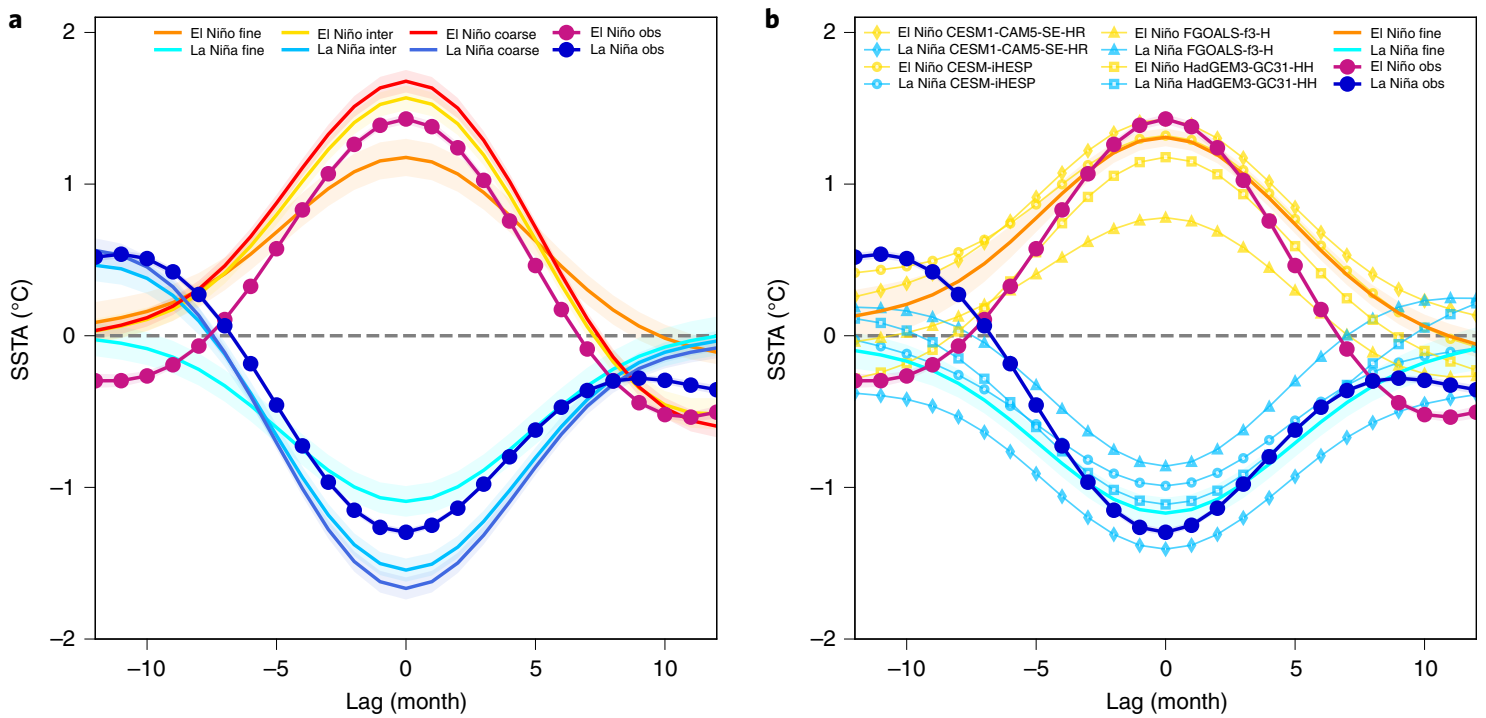

Fig. 4 | Dependence of ENSO amplitude on ocean model resolution. a, Multimodel averaged Niño3.4 SSTA evolution for El Niño and La Niña events in the coarse-resolution $\left(\geq 1^{\circ}\right)$, intermediate-resolution $\left(\sim 0.25^{\circ}\right)$ and fine-resolution $\left(\sim 0.1^{\circ}\right)$ CGCMs. Shadings denote the standard error of the multimodel ensemble average. b, Niño3.4 SSTA evolution for El Niño and La Niña events in the individual fine-resolution CGCMs with the dark orange and aqua lines denoting the multimodel average by excluding the member FGOALS- $f 3-\mathrm{H}$. The dark magenta and dark blue dot lines in $\mathbf{a}$ and $\mathbf{b}$ show the observational results.

the bias in simulated ENSO amplitude is probably due in part to the lack of effects from submesoscale eddies. This likelihood seems to be supported by the comparison of the ENSO amplitude in CGCM simulations with different ocean model resolutions in CMIP6 (Extended Data Table 1; see ENSO simulation in CGCMs with different ocean model resolutions in Methods). The multimodel ensemble mean amplitudes (measured as the maximum of SSTA magnitude) of El Niño and La Niña events in the coarse-resolution $\left(1^{\circ}\right.$ or coarser) CGCMs are overly large by about $20 \%$ and $30 \%$, respectively, compared with the observed amplitude (Fig. 4a).

The ENSO amplitude becomes progressively smaller as the oceanic resolution becomes finer, providing evidence for impacts from mesoscale and submesoscale eddies in simulated ENSO amplitude. For CGCMs with intermediate resolution $\left(\sim 0.25^{\circ}\right)$, in which mesoscale eddies are resolved but submesoscale eddies are only partially resolved ${ }^{22}$ (Extended Data Fig. 5), the ensemble mean ENSO amplitude remains overestimated. By contrast, the ensemble mean ENSO amplitude biases towards too small for the fine-resolution $\left(\sim 0.1^{\circ}\right)$ CGCMs resolving submesoscale eddies. This bias towards an overly small ENSO amplitude in the fine-resolution ensemble is due largely to one CGCM (FGOALS-f3-H) with a considerably smaller ENSO amplitude than that in the observations and other fine-resolution CGCMs (Fig. 4b), for reasons yet to be known. The ensemble mean ENSO amplitude with this outlier CGCM excluded agrees better with observations than those in the coarse- and intermediate-resolution CGCMs.

Although simulated ENSO amplitude is improved in fineresolution CGCMs, there is no clear improvement in simulated ENSO duration measured as the interval between zero crossings of SSTA during El Niño or La Niña events. In fact, the bias towards an overly long duration is slightly worse in this CESM-iHESP simulation than in CMIP6 CGCMs. However, this does not cast doubt on the importance of submesoscale eddies in damping ENSO. In fact, we find no significant intermodel correlation between simulated ENSO duration and amplitude. An improvement in simulated amplitude does not necessarily guarantee an improvement in simulated duration, and vice versa. The issue of whether and how submesoscale eddies affect ENSO duration remains unknown and requires future examination.
We recognize that there is only a small number of fine-resolution CGCMs currently available and that in addition to the difference between resolving submesoscale eddies and otherwise, CGCMs of different resolutions differ in many other ways. These include simulated climatological mean oceanic and atmospheric states, air-sea interactions and parameterizations of microscale turbulent mixing. Further, CGCMs with a higher oceanic resolution are typically accompanied by an increase in atmospheric resolution. Future studies based on an enlarged fine-resolution model ensemble and a designated design for isolating effects of submesoscale eddies are needed to comprehensively assess the role of submesoscale eddies in ENSO dynamics.

Our finding that equatorial submesoscale eddies inhibit ENSO growth by inducing an anomalous heat exchange between the subsurface and surface ocean injects a new element of consideration that classical ENSO theories have missed. Our result sheds light on the long-standing issue of an overly large ENSO amplitude in state-of-the-art CGCMs ${ }^{34,45,46}$. In addition, given the important role of submesoscale eddies in heating the surface equatorial Pacific mean state and in ENSO dynamics, this study highlights the need for their incorporation in CGCMs to reduce uncertainty in the projected change of the equatorial Pacific mean state and ENSO variability.

The important role of submesoscale eddies in inhibiting ENSO growth is missing in SST budget analysis based on reanalysis products $^{20,37,47-49}$. Ocean reanalysis is constructed on the basis of a numerical model integration constrained by atmospheric surface forcing and ocean observations via data assimilation methods ${ }^{50}$. Currently, the numerical models used are too coarse to resolve submesoscale eddies $^{20,37,47-49}$. By adjustment of model configuration or nudging to the observations, these models yield seemingly realistic simulation of ENSO characteristics but could still miss important underlying dynamical processes such as submesoscale eddies. The lack of effect of submesoscale eddies in these models might be compensated by a stronger dynamical damping, a weaker growth effect of microscale turbulent mixing than in reality or an artificial damping induced by data assimilation. Therefore, SST budget analysis based on coarse-resolution reanalysis products should be treated with caution. Future ocean reanalysis using numerical models that 
resolve submesoscale eddies will help improve the representation of dynamical processes controlling ENSO characteristics.

\section{Online content}

Any methods, additional references, Nature Research reporting summaries, source data, extended data, supplementary information, acknowledgements, peer review information; details of author contributions and competing interests; and statements of data and code availability are available at https://doi.org/10.1038/ s41561-021-00890-2.

Received: 25 February 2021; Accepted: 27 December 2021; Published online: 10 February 2022

\section{References}

1. Philander, S. G. El Niño, La Niña, and the Southern Oscillation (Academic Press, 1990).

2. McPhaden, M. J., Zebiak, S. E. \& Glantz, M. H. ENSO as an integrating concept in Earth science. Science 314, 1740-1745 (2006).

3. Patt, A. \& Glantz, M. H. Currents of change: impacts of El Niño and La Niña on climate and society. Int. J. Afr. Hist. Stud. 34, 173-174 (2001).

4. Ropelewski, C. F. \& Halpert, M. S. Global and regional scale precipitation patterns associated with the El Niño/Southern Oscillation. Mon. Weather Rev. 115, 1606-1626 (1987)

5. Cashin, P., Mohaddes, K. \& Raissi, M. Fair weather or foul? The macroeconomic effects of El Niño. J. Int. Econ. 106, 37-54 (2017)

6. Claar, D. C., Szostek, L., McDevitt-Irwin, J. M., Schanze, J. J. \& Baum, J. K. Global patterns and impacts of El Niño events on coral reefs: a meta-analysis. PLoS ONE 13, e0190957 (2018).

7. Cai, W. et al. Climate impacts of the El Niño-Southern Oscillation on South America. Nat. Rev. Earth Environ. 1, 215-231 (2020).

8. Lehodey, P. et al. in El Niño Southern Oscillation in a Changing Climate (eds McPhaden, M. J. et al.) 429-451 (Wiley, 2020).

9. Hoskins, B. J. \& Karoly, D. J. The steady linear response of a spherical atmosphere to thermal and orographic forcing. J. Atmos. Sci. 38, 1179-1196 (1981).

10. Bjerknes, J. Atmospheric teleconnections from the equatorial Pacific. Mon Weather Rev. 97, 163-172 (1969).

11. Neelin, J. D. et al. ENSO theory. J. Geophys. Res. Oceans 103, 14261-14290 (1998)

12. Jin, F. F. \& An, S. I. Thermocline and zonal advective feedbacks within the equatorial ocean recharge oscillator model for ENSO. Geophys. Res. Lett. 26 2989-2992 (1999).

13. Jin, F. F., Kim, S. T. \& Bejarano, L. A coupled-stability index for ENSO. Geophys. Res. Lett. 33, L23708 (2006).

14. Wang, C., Deser, C., Yu, J.-Y., DiNezio, P. \& Clement, A. in Coral Reefs of the Eastern Tropical Pacific (Glynn, P. W. et al.) 85-106 (Springer, 2017).

15. Suarez, M. J. \& Schopf, P. S. A delayed action oscillator for ENSO. J. Atmos. Sci. 45, 3283-3287 (1988).

16. Jin, F.-F. An equatorial ocean recharge paradigm for ENSO. Part I: conceptual model. J. Atmos. Sci. 54, 811-829 (1997).

17. Weisberg, R. H. \& Wang, C. A western Pacific oscillator paradigm for the El Niño-Southern Oscillation. Geophys. Res. Lett. 24, 779-782 (1997).

18. Picaut, J., Masia, F. \& Du Penhoat, Y. An advective-reflective conceptual model for the oscillatory nature of the ENSO. Science 277, 663-666 (1997).

19. Kim, S. T. \& Jin, F.-F. An ENSO stability analysis. Part II: results from the twentieth and twenty-first century simulations of the CMIP3 models. Clim. Dyn. 36, 1609-1627 (2011).

20. Boucharel, J. et al. A surface layer variance heat budget for ENSO. Geophys. Res. Lett. 42, 3529-3537 (2015)

21. Chelton, D. B., Wentz, F. J., Gentemann, C. L., de Szoeke, R. A. \& Schlax, M. G. Satellite microwave SST observations of transequatorial tropical instability waves. Geophys. Res. Lett. 27, 1239-1242 (2000).

22. Marchesiello, P., Capet, X., Menkes, C. \& Kennan, S. C. Submesoscale dynamics in tropical instability waves. Ocean Model. 39, 31-46 (2011)

23. Wang, S., Jing, Z., Liu, H. \& Wu, L. Spatial and seasonal variations of submesoscale eddies in the eastern tropical Pacific Ocean. J. Phys. Oceanogr 48, 101-116 (2018).

24. Willett, C. S., Leben, R. R. \& Lavín, M. F. Eddies and tropical instability waves in the eastern tropical Pacific: a review. Prog. Oceanogr. 69, 218-238 (2006).
25. An, S. I. Interannual variations of the tropical ocean instability wave and ENSO. J. Clim. 21, 3680-3686 (1980).

26. Jochum, M. \& Murtugudde, R. Temperature advection by tropical instability waves. J. Phys. Oceanogr. 36, 592-605 (2006)

27. Xue, A. et al. Delineating the seasonally modulated nonlinear feedback onto ENSO from tropical instability waves. Geophys. Res. Lett. 47, e2019GL085863 (2020).

28. Moum, J. et al. Sea surface cooling at the Equator by subsurface mixing in tropical instability waves. Nat. Geosci. 2, 761-765 (2009).

29. Holmes, R. M., Zika, J. D. \& England, M. H. Diathermal heat transport in a global ocean model. J. Phys. Oceanogr. 49, 141-161 (2019).

30. Holmes, R. \& Thomas, L. The modulation of equatorial turbulence by tropical instability waves in a regional ocean model. J. Phys. Oceanogr. 45 1155-1173 (2015).

31. Warner, S. J. \& Moum, J. N. Feedback of mixing to ENSO phase change. Geophys. Res. Lett. 46, 13920-13927 (2019).

32. Chang, P. et al. An unprecedented set of high-resolution Earth system simulations for understanding multiscale interactions in climate variability and change. J. Adv. Model. Earth Syst. 12, e2020MS002298 (2020).

33. Keenlyside, N. S. \& Latif, M. Understanding equatorial Atlantic interannual variability. J. Clim. 20, 131-142 (2007).

34. Planton, Y. Y. et al. Evaluating climate models with the CLIVAR 2020 ENSO metrics package. Bull. Am. Meteorol. Soc. 102, E193-E217 (2021).

35. Eyring, V. et al. Overview of the Coupled Model Intercomparison Project Phase 6 (CMIP6) experimental design and organization. Geosci. Model Dev. 9, 1937-1958 (2016)

36. Lee, T., Fukumori, I. \& Tang, B. Temperature advection: internal versus external processes. J. Phys. Oceanogr. 34, 1936-1944 (2004).

37. Guan, C., McPhaden, M. J., Wang, F. \& Hu, S. Quantifying the role of oceanic feedbacks on ENSO asymmetry. Geophys. Res. Lett. 46, 2140-2148 (2019).

38. Chen, L., Li, T. \& Yu, Y. Causes of strengthening and weakening of ENSO amplitude under global warming in four CMIP5 models. J. Clim. 28, 3250-3274 (2015).

39. Guan, C. \& McPhaden, M. J. Ocean processes affecting the twenty-firstcentury shift in ENSO SST variability. J. Clim. 29, 6861-6879 (2016).

40. Timmermann, A. et al. El Niño-Southern Oscillation complexity. Nature 559, 535-545 (2018)

41. Giordani, H., Prieur, L. \& Caniaux, G. Advanced insights into sources of vertical velocity in the ocean. Ocean Dyn. 56, 513-524 (2006).

42. Hoskins, B. J. The role of potential vorticity in symmetric stability and instability. Q. J. R. Meteorolog. Soc. 100, 480-482 (1974).

43. Fox-Kemper, B., Ferrari, R. \& Hallberg, R. Parameterization of mixed layer rddies. Part I: theory and diagnosis. J. Phys. Oceanogr. 38, 1145-1165 (2008).

44. McWilliams \& James, C. Submesoscale currents in the ocean. Proc. R. Soc. Lond. A 472, 20160117 (2016).

45. Bellenger, H., Guilyardi, É., Leloup, J., Lengaigne, M. \& Vialard, J. ENSO representation in climate models: from CMIP3 to CMIP5. Clim. Dyn. 42, 1999-2018 (2014).

46. Chen, X., Liao, H., Lei, X., Bao, Y. \& Song, Z. Analysis of ENSO simulation biases in FIO-ESM version 1.0. Clim. Dyn. 53, 6933-6946 (2019).

47. Huang, B., Xue, Y., Zhang, D., Kumar, A. \& McPhaden, M. J. The NCEP GODAS ocean analysis of the tropical Pacific mixed layer heat budget on seasonal to interannual time scales. J. Clim. 23, 4901-4925 (2010).

48. Hayashi, M. \& Jin, F. F. Subsurface nonlinear dynamical heating and ENSO asymmetry. Geophys. Res. Lett. 44, 12427-12435 (2017).

49. Chen, M. \& Li, T. ENSO evolution asymmetry: EP versus CP El Niño. Clim. Dyn. 56, 3569-3579 (2021).

50. Storto, A. \& Masina, S. C-GLORSv5: an improved multipurpose global ocean eddy-permitting physical reanalysis. Earth Syst. Sci. Data 8, 679-696 (2016).

Publisher's note Springer Nature remains neutral with regard to jurisdictional claims in published maps and institutional affiliations.

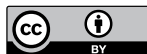

Open Access This article is licensed under a Creative Commons

Attribution 4.0 International License, which permits use, sharing, adaptation, distribution and reproduction in any medium or format, as long as you give appropriate credit to the original author(s) and the source, provide a link to the Creative Commons license, and indicate if changes were made. The images or other third party material in this article are included in the article's Creative Commons license, unless indicated otherwise in a credit line to the material. If material is not included in the article's Creative Commons license and your intended use is not permitted by statutory regulation or exceeds the permitted use, you will need to obtain permission directly from the copyright holder. To view a copy of this license, visit http://creativecommons. org/licenses/by/4.0/.

(c) The Author(s) 2022 


\section{Methods}

CESM-iHESP simulation. The long-term eddy-resolving climate simulation is completed at iHESP on the basis of CESM1.3. The atmosphere component is Community Atmosphere Model version 5 (CAM5), the ocean component is Parallel Ocean Program version 2 (POP2), the ice component is Community Ice Code version 4 and the land component is Community Land Model version 4. Nominal horizontal resolutions of CAM5 and POP2 are $0.25^{\circ}$ and $0.10^{\circ}$, respectively. There are 30 vertical levels in the atmosphere with a model top at $3 \mathrm{hPa}$. The ocean model has 62 vertical levels with a maximum depth of $6,000 \mathrm{~m}$. The simulation consists of a $500 \mathrm{yr}$ pre-industry control (PI-CTRL) simulation and a $250 \mathrm{yr}$ HF-TNST simulation, following the design protocol of the CMIP5 experiments.

For the PI-CTRL simulation, the ocean component was initialized with January-mean climatological potential temperature and salinity from the World Ocean Atlas. The climate forcings were set constantly to the 1850 conditions throughout the entire $500 \mathrm{yr}$ simulation. The HF-TNST simulation was branched out from the year 250 of the PI-CTRL simulation, using historical forcings from 1850 to 2005 and the representative concentration pathway 8.5 forcing from 2006 to 2100 . Importantly, the commonly known cold-tongue bias is alleviated in the CESM-iHESP simulation, and the simulated ENSO pattern agrees reasonably well with reanalysis products (Fig. 1 and Extended Data Fig. 3). More details can be found in an overview paper for this simulation ${ }^{32}$

The CESM-iHESP simulation saves monthly surface fluxes and diagnostic outputs for the temperature-governing equation after 1878, except horizontal and vertical mixing terms. Daily averaged outputs are available after 1938 for oceanic velocity, temperature and salinity at sea surface and vertical velocity, temperature and salinity at selected depth levels $(50,105,528$ and 1,146 m). To analyse the underlying dynamics of the vertical submesoscale eddy heat flux in the equatoria Pacific Ocean, complete daily averaged diagnostic outputs for the temperature-, salinity- and momentum-governing equations are saved for 1920-1929, with 1923 and 1928 corresponding to La Niña and El Niño years, respectively.

Reanalysis and observation products. To assess the performance of CESMiHESP in ENSO simulation, we use three reanalysis products containing SST, sea surface height and wind stress: JPL ECCO-V4r4 (ECCO4) covering the period 1992-2017 $7^{51}$, GODAS covering the period $1980-2020^{52}$ and ORA-S5 covering the period 1979-2017 $7^{53}$. The observational ENSO amplitude shown in Fig. 4 is computed on the basis of three SST observation products: DASK ${ }^{54}$, ERSST $5^{55}$ and HadISST ${ }^{56}$. To be consistent with the period of historical simulations in CMIP6, we use only the data between 1950 and 2014 except for DASK, which ends in 2012

SST budget. Vertical mean temperature in the upper $50 \mathrm{~m}$ is used as a proxy for SST. A heat budget for the upper $50 \mathrm{~m}$ can be derived as:

$$
\begin{gathered}
\left\langle\int_{-h}^{0} \rho_{0} C_{P} \overline{\frac{\partial T}{\partial t}} d z\right\rangle=-\left\langle\int_{-h}^{0} \rho_{0} C_{P} \nabla \cdot(\overline{\mathbf{u}} \bar{T}) d z\right\rangle-\left\langle\int_{-h}^{0} \rho_{0} C_{P} \nabla_{h} \cdot\left(\overline{\mathbf{u}_{h}^{\prime} T^{\prime}}\right) d z\right\rangle \\
\text { TD } \\
+\left.\left\langle\rho_{0} C_{P} \overline{W^{\prime} T^{\prime}}\right\rangle\right|_{z=-h}+\left\langle\int_{-h}^{0} \rho_{0} C_{P} \kappa_{h} \nabla_{h}^{2} \bar{T} d z-\int_{-h}^{0} \rho_{0} C_{P} \kappa_{4} \nabla_{h}^{4} \bar{T} d z\right\rangle \\
Q_{\text {eddy, }}
\end{gathered}
$$$$
+\left\langle Q_{\text {shf }}\right\rangle+\left\langle Q_{\text {turb }}\right\rangle
$$

where $h=50 \mathrm{~m}$ is the lower bound for the vertical integration, $T$ is potential temperature, $\mathbf{u}=\left(\mathbf{u}_{h}, w\right)$ is a three-dimensional velocity vector, with $\mathbf{u}_{h}=(u, v)$ being its horizontal component and $w$ its vertical component, $\nabla=(\partial / \partial x, \partial / \partial y, \partial / \partial z), \nabla_{h}=(\partial / \partial x, \partial / \partial y), \kappa_{h}$ is the horizontal diffusion coefficient, $\kappa_{4}$ is the horizontal biharmonic diffusion coefficient, $\rho_{0}=1,027.5 \mathrm{~kg} \mathrm{~m}^{-3}$ is ocean reference density, $C_{p}$ is ocean specific heat capacity, $Q_{\mathrm{shf}}$ is ocean heat uptake from the atmosphere (the sea surface heat flux defined positive into the ocean) and $Q_{\text {turb }}$ is parameterized microscale turbulent mixing (the vertical turbulent heat flux at $50 \mathrm{~m}$ defined positive into the upper ocean). The overbar denotes the monthly mean value, the prime denotes the perturbation from the monthly mean value and $\langle\ldots\rangle$ denotes the spatial average over the Niño3.4 region. To isolate ENSO variability, each term in equation (1) is first subtracted by its linear trend and climatological seasonal cycle, and then low-pass filtered with a cut-off period of 12 months. Dividing individual terms in equation (1) by $\rho_{0} C_{P} h$ converts the heat budget into the SST budget.

Both $\overline{\mathbf{u}}$ and $\bar{T}$ are available in the model outputs, in which case the heat flux by monthly mean flows can be directly calculated. The heat flux by perturbed flows is derived by subtracting the heat flux by monthly mean flows from the model's diagnostic outputs for advective heat flux. There is a horizontal scale separation between the monthly mean flows and their perturbations. The heat-flux convergence of monthly mean flows (the first term on the right-hand side of equation (1)), is attributed mostly to motions with horizontal wavelengths larger than $1,600 \mathrm{~km}$ (Extended Data Fig. 6). For this reason, we equate the monthly mean flows with the basin-scale flows and denote the first term as $Q_{\text {basin }}$.
By contrast, the horizontal heat-flux convergence (the second term, denoted as $Q_{\text {eddy,h }}$ ) and vertical heat flux at $50 \mathrm{~m}$ (the third term, denoted as $Q_{\text {eddyv }}$ ) by perturbed flows are almost contributed by motions with horizontal wavelengths smaller than 1,600 km (Extended Data Fig. 5), indicating the equivalence between the perturbed flows and sub-basin-scale eddies. Note that $Q_{\text {basin, }}, Q_{\text {eddy,h }}$ and $Q_{\text {eddy, }}$ are unambiguous as they are all independent from the arbitrary reference of zero temperature ${ }^{36}$

The $Q_{\text {turb }}$ is not available in the model outputs except for 1920-1929. It is computed as a residue of equation (1) that also contains the contribution from horizontal mixing and other numerical processes. The value of $Q_{\text {turb }}$ at $50 \mathrm{~m}$ computed explicitly from the diagnostic output is compared with that inferred from the residue of equation (1) during 1920-1929. Their time series are almost identical, with a correlation coefficient above 0.99 . This provides strong evidence that the residue is equivalent to $Q_{\text {turb }}$ in practice.

Separating effects from mesoscale and submesoscale eddies. Cross-spectral analysis is performed to separate contribution from mesoscale and submesoscale eddies to $Q_{\text {eddyv }}$ and $Q_{\text {eddyh }}$. The value of $Q_{\text {eddyv }}$ is decomposed in the horizontal wavenumber space as:

$$
Q_{\text {eddy,v }}=\rho_{0} C_{P} \Re \int_{0}^{\infty} \Psi_{w^{\prime} T^{\prime}}\left(k_{H}\right) d k_{H}
$$

where $\Psi_{w / T}$, represents cross spectrum for $w^{\prime}$ and $T^{\prime}$ at $50 \mathrm{~m}$ over the Niño3.4 region, $k_{H}$ is horizontal wavenumber magnitude and $\Re$ is a real operator. Then the fraction of $Q_{\text {eddy, }}$ contributed by motions with $k_{H}$ larger than some critical value $k_{H}^{c}$ is measured as $r_{v}=Q_{\text {eddy,v }}\left(k_{H}^{c}\right) / Q_{\text {eddy,v }}$, where $Q_{\text {eddy, }}\left(k_{H}^{c}\right)$ is derived from replacing the lower limit of integral in equation (2) by $k_{H}^{c}$. As to $Q_{\text {eddy,h }}$, we first re-express it as $-\left\langle\int_{-h}^{0} \rho_{0} C_{P}\left(\overline{\mathbf{u}_{h^{\prime}} \cdot \nabla_{h} T \prime}+\overline{\left.T / \nabla_{h} \cdot \mathbf{u}_{h^{\prime}}\right)}\right) d z\right\rangle$ and then decompose it in the horizontal wavenumber space as:

$$
Q_{\text {eddy, } \mathrm{h}}=-\rho_{0} C_{P} \int_{-h}^{0} \Re \int_{0}^{\infty} \Psi_{u^{\prime} \partial T^{\prime}}+\Psi_{v^{\prime} \partial T^{\prime}}+\Psi_{T^{\prime} \partial u^{\prime}}+\Psi_{T^{\prime} \partial v^{\prime}} d k_{H} d z
$$

where $\Psi_{u^{\prime} \partial T^{\prime}}$ is cross spectrum for $u^{\prime}$ and $\partial T^{\prime} \partial x$, and similarly for $\Psi_{v^{\prime} \partial T^{\prime}}, \Psi_{T^{\prime} \partial u^{\prime}}$ and $\Psi_{T^{\prime}} \partial v^{\prime}$. Finally, the fraction of $Q_{\text {eddy, }}$ contributed by motions with $k_{H}$ larger than $k_{H}^{c}$ is measured as $r_{\mathrm{h}}=Q_{\text {eddy, }}\left(k_{H}^{c}\right) / Q_{\text {eddy,h }}$.

Once $r_{\mathrm{v}}$ and $r_{\mathrm{h}}$ are obtained as a function of $k_{H}^{c}$ according to equations (2) and (3), mesoscale and submesoscale eddies' effects can be separated by setting $k_{H}^{c}$ as the cut-off wavenumber between these two scale ranges (Extended Data Fig. 5). Specifically, the values of $Q_{\text {eddy }}^{\text {sub }}$ and $Q_{\text {eddy }}^{\text {meso }}\left(Q_{\text {eddyh }}^{\text {sub }}\right.$ and $\left.Q_{\text {eddy }}^{\text {mes }}\right)$ are defined as $r_{\mathrm{v}} Q_{\text {eddy,v }}$ and $\left(1-r_{\mathrm{v}}\right) Q_{\text {eddy, }}\left(r_{\mathrm{h}} Q_{\text {eddy, }}\right.$ and $\left.\left.\left(1-r_{\mathrm{h}}\right) Q_{\text {eddy, }}\right)\right)$, respectively. The lower scale (wavelength) bound for equatorial mesoscale eddies (TIWs and TIVs) is typically defined as $600 \mathrm{~km}$ or so according to existing literature ${ }^{24,57,58}$. Therefore, we choose $600 \mathrm{~km}$ as the cut-off wavelength (corresponding to a cut-off wavenumber around $10^{-5} \mathrm{rad} \mathrm{m}^{-1}$ ) to separate mesoscale and submesoscale eddies. Such definition of submesoscale is comparable to the mixed-layer deformation radius multiplied by a factor of $2 \pi$ in the equatorial Pacific Ocean (here the factor of $2 \pi$ is included because the scale is measured as wavelength), with the latter being a widely used measurement of submesoscale ${ }^{44,59}$ (Extended Data Fig. 1). Note that a slight change of the cut-off wavelength does not undermine the important role of submesoscale eddies in damping ENSO.

Daily averaged model outputs for $u, v, w$ and $T$ are used to estimate $u^{\prime}, v^{\prime}, w^{\prime}$ and $T^{\prime}$. This neglects the contribution of higher-frequency motions to perturbed internal gravity waves, they are not supposed to contribute to the heat flux.

Decomposing $Q_{\text {basin }}$ into different feedbacks and damping mechanisms. To assess the role of $Q_{\text {eddy, }}^{\text {sub }}$ in the ENSO life cycle relative to the basin-scale feedbacks and damping mechanisms proposed in the classical ENSO theories, $Q_{\text {basin }}$ is further decomposed into the following components:

$$
\begin{array}{rr}
-\left\langle\int_{-h}^{0} \rho_{0} C_{P} \nabla \cdot(\overline{\mathbf{u}} \bar{T}) d z\right\rangle=\left\langle\left.\rho_{0} C_{P} \tilde{w} T^{*}\right|_{z=-h}\right\rangle & -\left\langle\int_{-h}^{0} \rho_{0} C_{P} u^{*} \frac{\partial \tilde{T}}{\partial x} d z\right\rangle \\
\text { thermocline feedback } & \text { zonal advection feedback } \\
-\left\langle\int_{-h}^{0} \rho_{0} C_{P} v^{*} \frac{\partial \tilde{T}}{\partial y} d z\right\rangle & -\left\langle\int_{-h}^{0} \rho_{0} C_{P} w^{*} \frac{\partial \tilde{T}}{\partial z} d z\right\rangle
\end{array}
$$

meridional advection feedback Ekman feedback

$$
\begin{gathered}
-\left\langle\int_{-h}^{0} \rho_{0} C_{P} u^{*} \frac{\partial T^{*}}{\partial x} d z+\int_{-h}^{0} \rho_{0} C_{P} v^{*} \frac{\partial T^{*}}{\partial y} d z+\int_{-h}^{0} \rho_{0} C_{P} w^{*} \frac{\partial T^{*}}{\partial z} d z\right\rangle \\
\text { nonlinear dynamical heating } \\
-\left\langle\int_{-h}^{0} \rho_{0} C_{P} \frac{\partial \tilde{u} T^{*}}{\partial x} d z+\int_{-h}^{0} \rho_{0} C_{P} \frac{\partial \tilde{\tilde{\tau}} T^{*}}{\partial y} d z\right\rangle \\
\text { dynamical damping } \\
-\left\langle\int_{-h}^{0} \rho_{0} C_{P} \tilde{u} \frac{\partial \tilde{T}}{\partial x} d z+\int_{-h}^{0} \rho_{0} C_{P} \tilde{v} \frac{\partial \tilde{T}}{\partial y} d z+\int_{-h}^{0} \rho_{0} C_{P} \tilde{w} \frac{\partial \tilde{T}}{\partial z} d z\right\rangle
\end{gathered}
$$


where $\bar{X}=\tilde{X}+X^{*}$, with the tilde representing the climatological seasonal cycle and the asterisk representing the anomalies. The first term on the right-hand side of equation (4) corresponds to the thermocline feedback, the second term the zonal advection feedback, the third term the meridional advection feedback, the fourth term the Ekman feedback, the fifth term the nonlinear dynamical heating and the sixth term the dynamical damping. The last term does not vary at interannual scales and thus has no effect on ENSO.

Decomposing vertical submesoscale eddy heat flux into different ocean dynamics. The PE omega equation is used to evaluate the major generation mechanisms of $Q_{\text {eddy, }}^{\text {sub }}$

$$
\begin{aligned}
& f^{2} \frac{\partial^{2} w}{\partial z^{2}}+\nabla_{h} \cdot\left(N^{2} \nabla_{h} w\right)=F_{\mathrm{dia}}+F_{\mathrm{vc}}+F_{\mathrm{kd}}+F_{\mathrm{twi}}+F_{\mathrm{dr}}+F_{\text {beta }} \\
& F_{\mathrm{dia}}=\nabla_{h} \cdot\left(\frac{\partial}{\partial x} D(b), \frac{\partial}{\partial y} D(b)\right) \\
& F_{\mathrm{vc}}=\nabla_{h} \cdot\left(-f \frac{\partial}{\partial z} D(v), f \frac{\partial}{\partial z} D(u)\right) \\
& F_{\mathrm{kd}}=-\nabla_{h} \cdot 2\left(\frac{\partial u}{\partial x} \frac{\partial b}{\partial x}+\frac{\partial v}{\partial x} \frac{\partial b}{\partial y}, \frac{\partial u}{\partial y} \frac{\partial b}{\partial x}+\frac{\partial v}{\partial y} \frac{\partial b}{\partial y}\right) \\
& F_{\mathrm{twi}}=\nabla_{h} \cdot\left(f\left(\frac{\partial v}{\partial x} \frac{\partial u_{a g}}{\partial z}-\frac{\partial u}{\partial x} \frac{\partial v_{a g}}{\partial z}\right), f\left(\frac{\partial v}{\partial y} \frac{\partial u_{a g}}{\partial z}-\frac{\partial u}{\partial y} \frac{\partial v_{a g}}{\partial z}\right)\right) \\
& F_{d r}=\nabla_{h} \cdot\left(\frac{d}{d t}\left(f \frac{\partial v_{a g}}{\partial z}\right),-\frac{d}{d t}\left(f \frac{\partial u_{a g}}{\partial z}\right)\right) \\
& F_{b e t a}=\nabla_{h} \cdot\left(-\beta v \frac{\partial v}{\partial z}, \beta v \frac{\partial u}{\partial z}\right)+f \beta \frac{\partial v}{\partial z}+f \beta \frac{\partial v_{a g}}{\partial z}
\end{aligned}
$$

where $b=-g \rho_{0}^{-1}\left(\rho-\rho_{0}\right)$ is buoyancy with $g$ being the gravitational acceleration and $\rho$ the potential density, $f$ is the Coriolis parameter varying with the latitude, $D(u) / D(v)$ is the turbulent mixing term for zonal/meridional momentum, $D(b)$ is the turbulent mixing term for buoyancy, $\left(u_{\mathrm{g}}, v_{\mathrm{g}}\right)$ are the geostrophic flows and $\left(u_{\mathrm{ag}}, v_{\mathrm{ag}}\right)=\left(u-u_{\mathrm{g}}, v-v_{\mathrm{g}}\right)$ are the horizontal components of ageostrophic flows.

Equation (5) is similar to the one proposed by ref. ${ }^{41}$ except that it additionally allows for a varying $f$ to ensure its applicability to the equatorial region. The first and second terms on the right-hand side of equation (5) correspond to diabatic and viscous effects, respectively. The third term corresponds to the kinematic deformation by the total flow and is attributed mainly to the mixed-layer instability and frontogenesis ${ }^{42,43,60}$. The mixed-layer instability is a type of baroclinic instability developing in the weakly stratified surface mixed layer at fronts ${ }^{43,4,59}$. The most unstable modes occur at ocean submesoscales. As a type of baroclinic instability, the energy is first transferred from the mean available potential energy to EAPE and then from EAPE to EKE, resulting in an upward eddy heat (buoyancy) flux in the upper ocean ${ }^{59}$. During frontogenesis, squeezing of a surface submesoscale front by background confluent flows increases the horizontal temperature (buoyancy) gradient. To restore the thermal wind balance, an ageostrophic secondary circulation with upwelling (downwelling) on the warmer (colder) side of the front is induced. This produces an upward eddy heat flux in the upper ocean associated with the conversion from EAPE to EKE. Readers are advised to refer to refs. ${ }^{43,44}$ for schematic plots of upward eddy heat flux induced by the mixed-layer instability and frontogenesis. The fourth term denotes the deformation caused by the thermal wind imbalance. The fifth term denotes forcing by a material derivative of the thermal wind imbalance. The last term is attributed to the $\beta$ effect $(\beta=\partial f / \partial y)$. Due to the linear nature of equation (5), its solution can be decomposed linearly into seven components with distinct dynamics.

$$
w=w_{\text {dia }}+w_{\mathrm{vc}}+w_{\mathrm{kd}}+w_{\mathrm{twi}}+w_{\mathrm{dr}}+w_{\text {beta }}+w_{\text {bou }}
$$

The first six terms on the right-hand side of equation (6) represent sequentially the contribution from individual forcing terms of equation (5), solved by keeping only the corresponding forcing term and adopting the homogeneous boundary condition. The solution $w_{\text {bou }}$ represents the contribution from boundary condition and is obtained by dropping all the forcing terms but using the model output as the boundary condition of $w$. The PE omega equation is solved in the upper $200 \mathrm{~m}$ over a domain $\left(10^{\circ} \mathrm{S}-10^{\circ} \mathrm{N}\right.$ and $\left.175^{\circ} \mathrm{W}-125^{\circ} \mathrm{W}\right)$ larger than the Niño3.4 region to suppress the boundary effects.

ENSO simulation in CGCMs with different ocean model resolutions. At the time of writing this manuscript, there are 72 CGCMs that are forced with historical anthropogenic and natural forcings in CMIP6 with their data downloadable from the Internet. A CGCM is classified as a coarse-resolution one if the zonal resolution of its ocean component in the equatorial region $\left(\Delta_{\text {lon }}\right)$ is around $1^{\circ}$ or coarser, as an intermediate-resolution one if $\Delta_{\operatorname{lon}}$ is around $0.25^{\circ}$ and as a fine-resolution one if $\Delta_{\text {lon }}$ is around $0.1^{\circ}$. This way of classification yields 47 coarse-resolution, 12 intermediate-resolution and 4 fine-resolution CGCMs. CGCMs whose Niño3.4 SST spectrum does not exhibit any significant (at the $99 \%$ confidence level) peak at two to eight years are discarded as they are not able to simulate basic ENSO characteristics. A relatively stringent confidence level is used as we test against pseudo peaks not at a particular period but within a broad period range. Applying this criterion removes two coarse-resolution CGCMs (INM-CM-4-8 and NESM3) and one fine-resolution CGCM (INM-CM-5-H). Finally, we add our CESM-iHESP simulation to the fine-resolution ensemble. The final 61 CGCMs used in this study are listed in Extended Data Table 1. Length of simulation differs among CGCMs, and ENSO amplitudes shown in Fig. 4 are derived from their overlapping period (1950-2014). Standard error of the ensemble mean (the shading shown in Fig. 4) is computed by assuming independence among CGCMs as:

$$
\sigma_{e}=\sqrt{\frac{1}{N-1} \sum_{i=1}^{N}\left(A_{i}-\bar{A}\right)^{2} / \sqrt{N}}
$$

where $A_{i}$ is the value of the $i$-th ensemble member, $N$ is ensemble number, and $\bar{A}$ is ensemble mean.

\section{Data availability}

The CESM data used in this work are available from both iHESP data portal (https://ihesp.tamu.edu/) and QNLM data portal (http://ihesp.qnlm.ac). The CMIP6 model data can be downloaded from https://esgf-node.llnl.gov/search/ cmip6/. The ECCO4, ORA-S5, GODAS, DASK, ERSST v5 and HadISST data can be downloaded from http://apdrc.soest.hawaii.edu/. The VIIRS-L3M data can be downloaded from https://oceandata.sci.gsfc.nasa.gov/. Source data are provided with this paper.

\section{Code availability}

The iHESP version of the CESM code is available at ZENODO via https://doi.org/ 10.5281/zenodo.3637771. The Python3.8 is used for plotting.

\section{References}

51. Forget, G. et al. ECCO version 4: an integrated framework for non-linear inverse modeling and global ocean state estimation. Geosci. Model Dev. 8, 3071-3104 (2015).

52. Behringer, D. \& Xue, Y. Evaluation of the global ocean data assimilation system at NCEP: the Pacific Ocean. In Proc. Eighth Symposium on Integrated Observing and Assimilation Systems for Atmosphere, Oceans, and Land Surface (2004).

53. Zuo, H., Balmaseda, M. A., Tietsche, S., Mogensen, K. \& Mayer, M. The ECMWF operational ensemble reanalysis-analysis system for ocean and sea ice: a description of the system and assessment. Ocean Sci. 15, 779-808 (2019)

54. Kim, Y. H., Hwang, C. \& Choi, B.-J. An assessment of ocean climate reanalysis by the data assimilation system of KIOST from 1947 to 2012. Ocean Model. 91, 1-22 (2015).

55. Huang, B. et al. Extended reconstructed sea surface temperature, version 5 (ERSSTv5): upgrades, validations, and intercomparisons. J. Clim. 30, 8179-8205 (2017).

56. Rayner, N. et al. Global analyses of sea surface temperature, sea ice, and night marine air temperature since the late nineteenth century. J. Geophys. Res. Atmos. 108, D14 (2003).

57. Flament, P. J., Kennan, S. C., Knox, R. A., Niiler, P. P. \& Bernstein, R. L. The three-dimensional structure of an upper ocean vortex in the tropical Pacific Ocean. Nature 383, 610-613 (1996).

58. Contreras, R. F. Long-term observations of tropical instability waves. J. Phys. Oceanogr. 32, 2715-2722 (2002).

59. Boccaletti, G., Ferrari, R. \& Fox-Kemper, B. Mixed layer instabilities and restratification. J. Phys. Oceanogr. 37, 2228-2250 (2007).

60. Yang, P. et al. On the upper-ocean vertical eddy heat transport in the Kuroshio extension. Part I: variability and dynamics. J. Phys. Oceanogr. 51, 229-246 (2021)

\section{Acknowledgements}

This work is supported by the National Natural Science Foundation of China (41822601, 41776006 and 42006011) and completed through the iHESP, a collaboration by the Qingdao National Laboratory for Marine Science and Technology Development Center, Texas A\&M University and the National Center for Atmospheric Research. Computation for the work described in this paper is supported by the iHESP and Pilot National Laboratory for Marine Science and Technology (Qingdao). National Center for Atmospheric Research is a major facility sponsored by the US National Science Foundation under Cooperative Agreement 1852977. We thank T. Du for assisting in plotting figures.

\section{Author contributions}

S.W. conducted the analysis under Z.J's instruction. Z.J. proposed the central idea. L.W. led the research and organized writing of the manuscript. S.W., Z.J. and W.C. wrote the manuscript. P.C. and T.G. contributed to the writing of the manuscript. H.W. performed the CESM-iHESP simulation. All authors were involved in interpreting the results and contributed to improving the manuscript.

\section{Competing interests}

The authors declare no competing interests. 


\section{Additional information}

Extended data is available for this paper at https://doi.org/10.1038/s41561-021-00890-2.

Supplementary information The online version contains supplementary material available at https://doi.org/10.1038/s41561-021-00890-2.

Correspondence and requests for materials should be addressed to Zhao Jing.
Peer review information Nature Geoscience thanks Sally Warner, Patrice Klein and the other, anonymous, reviewer(s) for their contribution to the peer review of this work. Primary Handling Editor: Thomas Richardson, in collaboration with the Nature Geoscience team.

Reprints and permissions information is available at www.nature.com/reprints. 


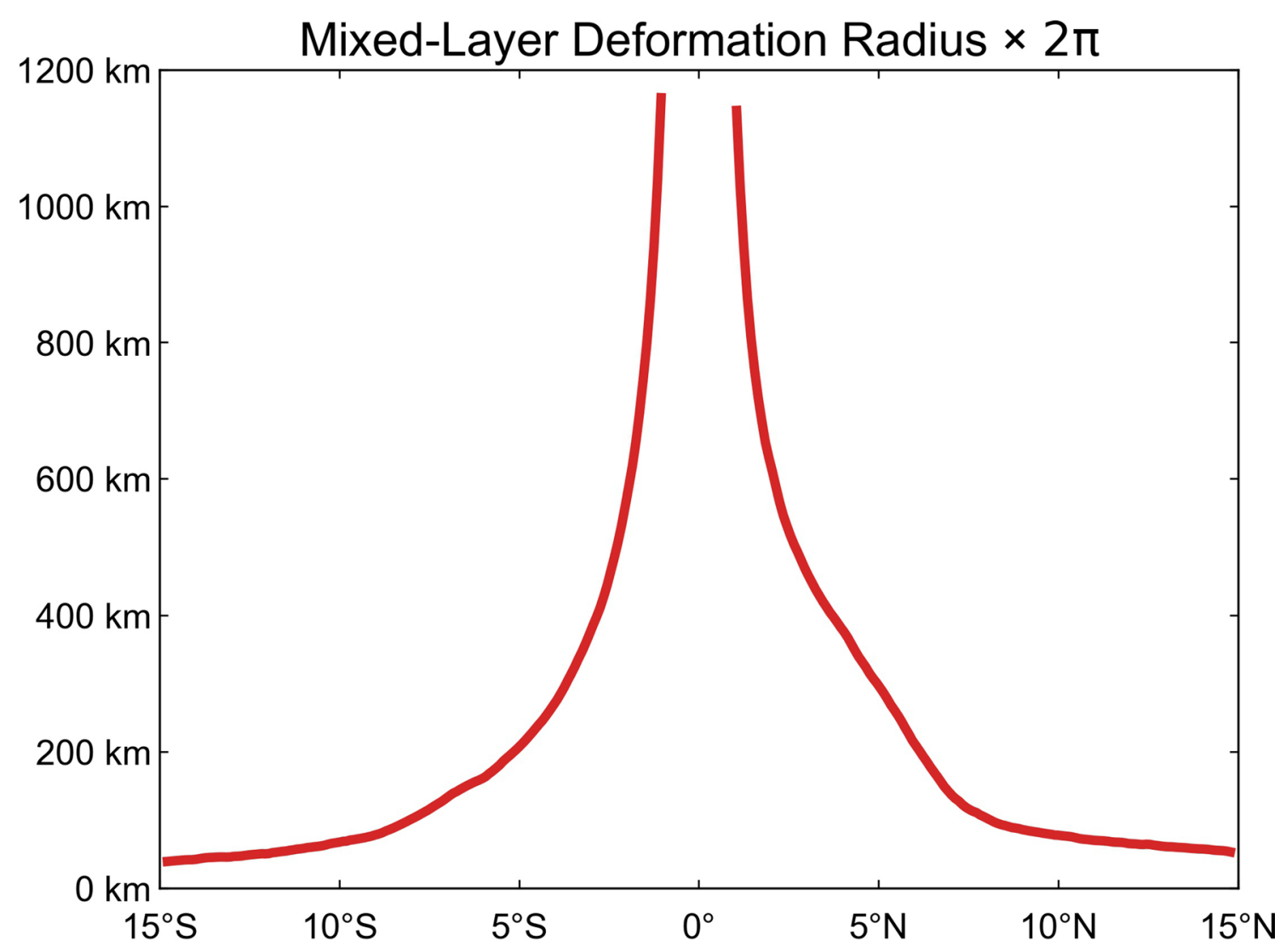

Extended Data Fig. 1 | Meridional distribution of the mixed-layer deformation radius multiplied by a factor of $2 \pi$, a widely used measurement of the submesoscale. The result is derived from the CESM-iHESP simulation and is averaged over the $170^{\circ} \mathrm{W}-120^{\circ} \mathrm{W}$ range. The factor of $2 \pi$ is included because the scale in this study is measured as the horizontal wavelength. 


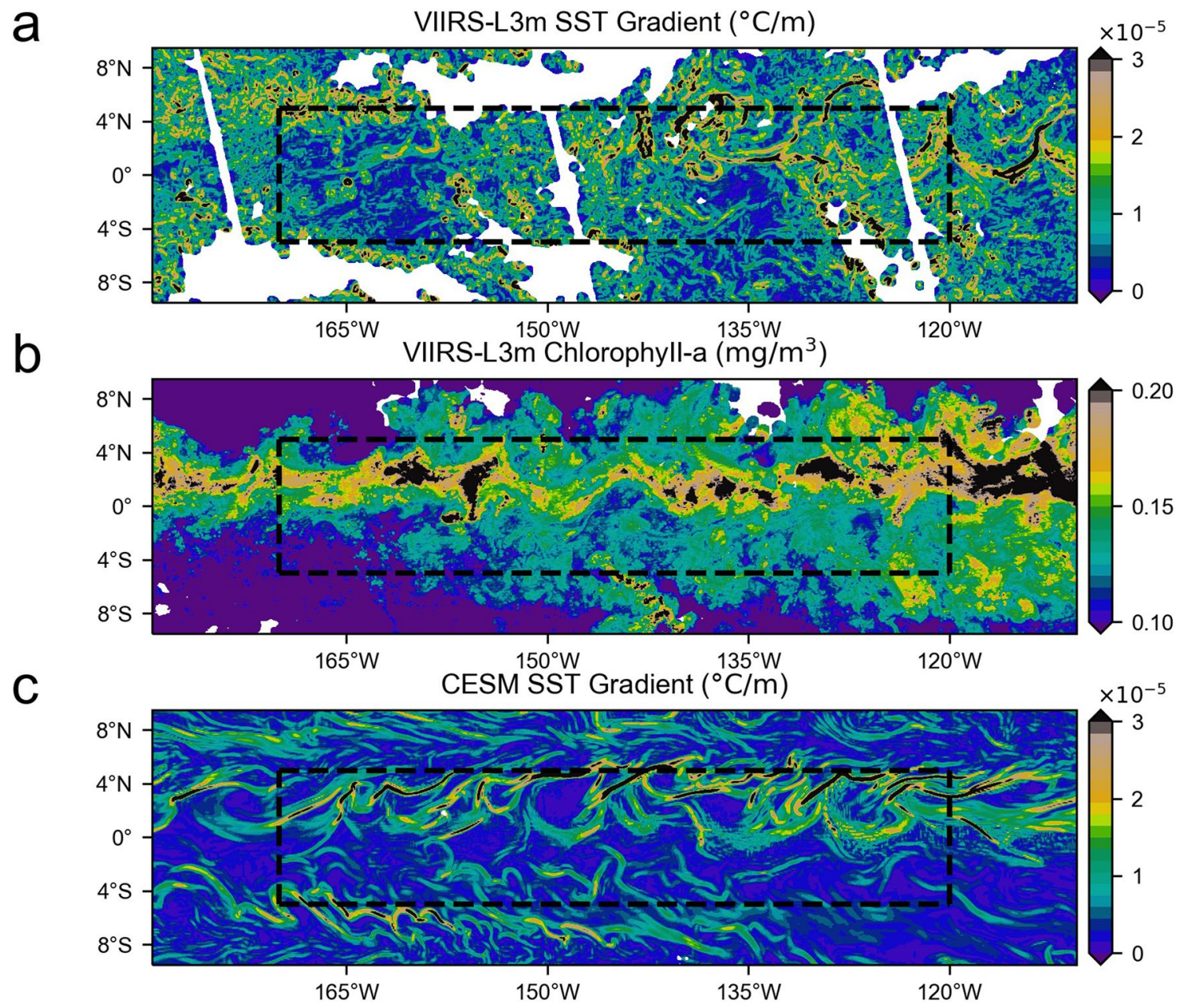

Extended Data Fig. 2 | Equatorial submesoscale eddies in the observations and CESM-iHESP simulation. Snapshots of a, observational horizontal SST gradient magnitude, b, Chlorophyll-a at the surface derived from VIIRS on October 1st, 2019, and c, simulated horizontal SST gradient magnitude on October 1st, 2018 in the CESM-iHESP simulation. October 1st, 2019 is in a neutral phase of the observed ENSO, as is the case for October 1st, 2018 in the CESM-iHESP simulation. 


\section{NATURE GEOSCIENCE}

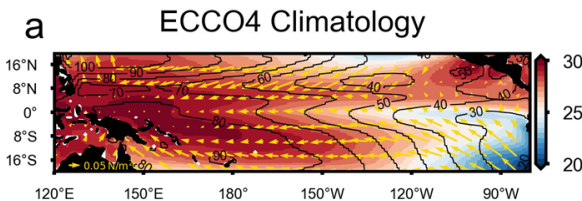

b

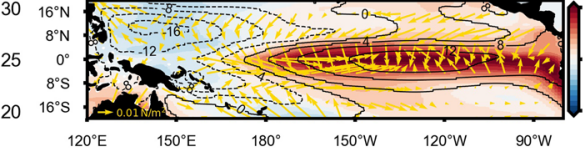

d GODAS Climatology

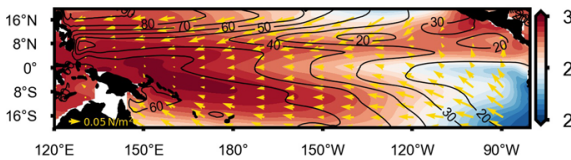

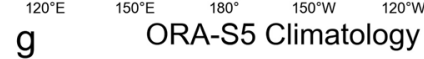
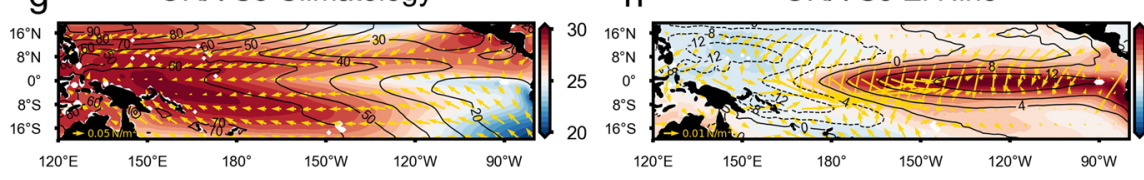

C

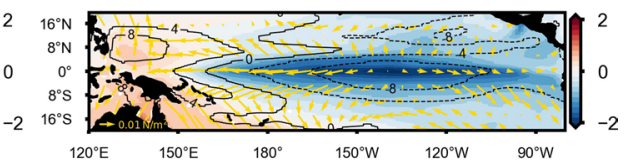

$f$

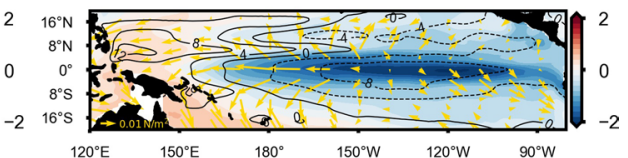

$i^{120}$
ORA-S5 La Niña

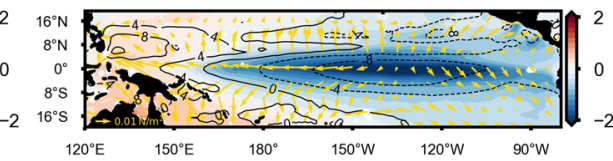

Extended Data Fig. 3 | ENSO characteristics derived from reanalysis products. a, b, c, Climatological mean SST in ${ }^{\circ} \mathrm{C}$ (shading), sea surface height in cm (contours) and wind stress in $\mathrm{N} \mathrm{m}^{-2}$ (vectors) based on the ECCO4 data, and the composite of their anomalies at the peak El Niño and La Niña events. $\mathbf{d}$, e, $\mathbf{f}$, and $\mathbf{g}, \mathbf{h}, \mathbf{i}$, Same as $\mathbf{a}, \mathbf{b}, \mathbf{c}$, but for the GODAS data and ORA-S5 data, respectively. 


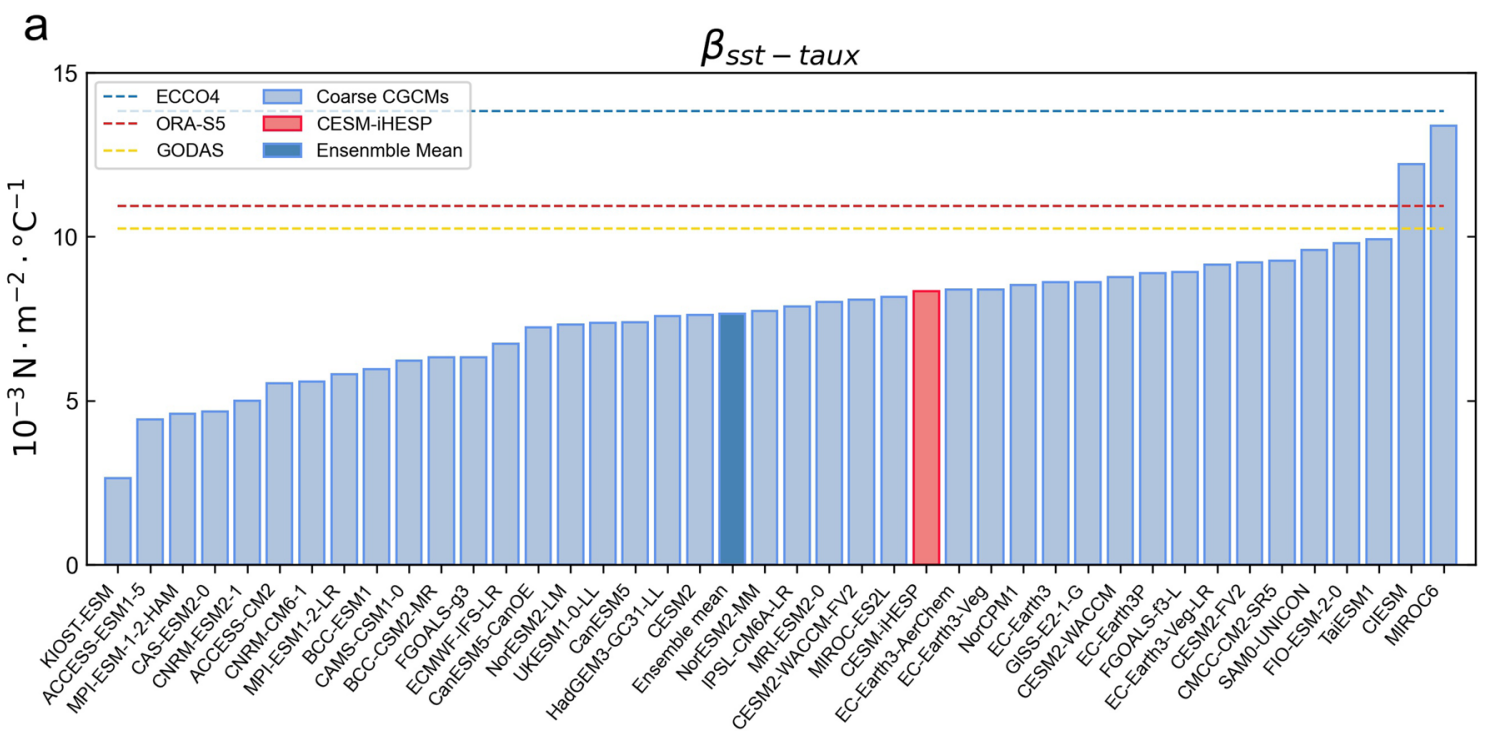

b
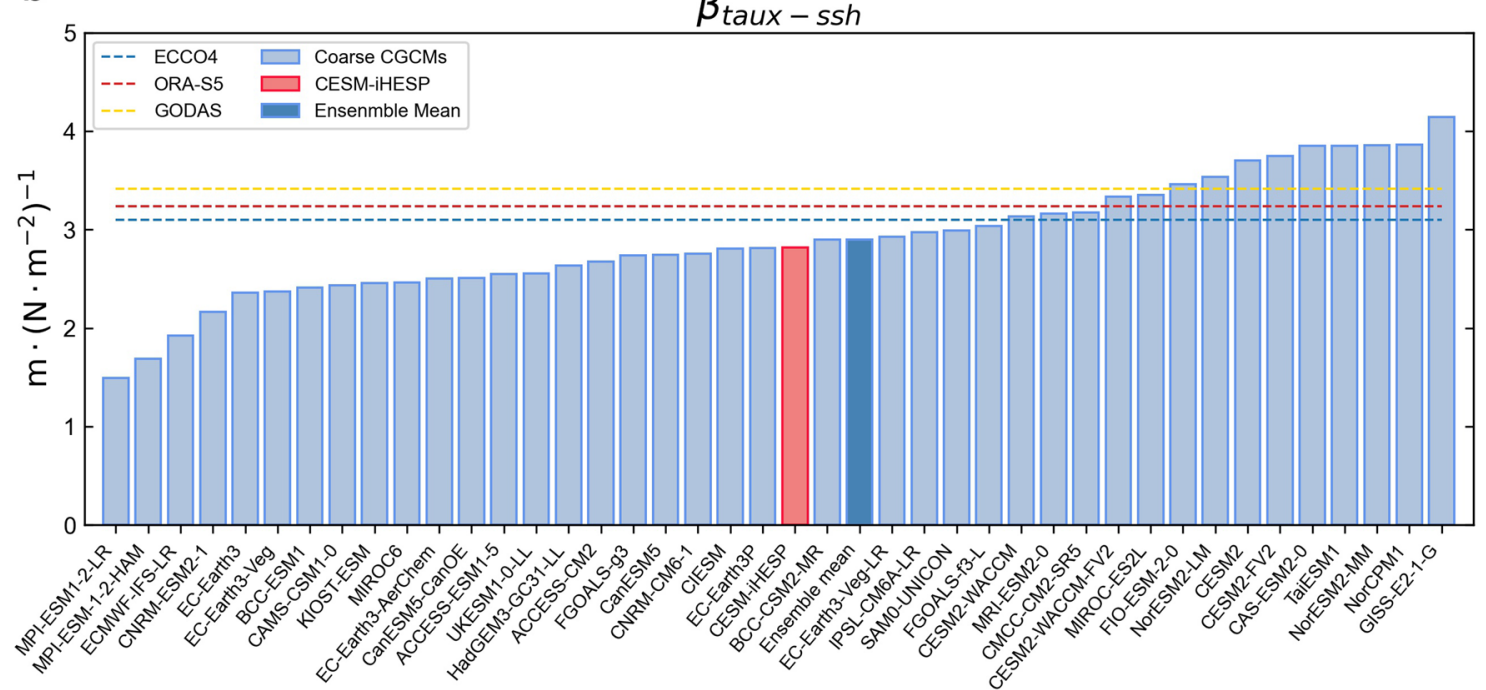

$\mathrm{C}$

$\beta_{\text {ssh-sst }}$

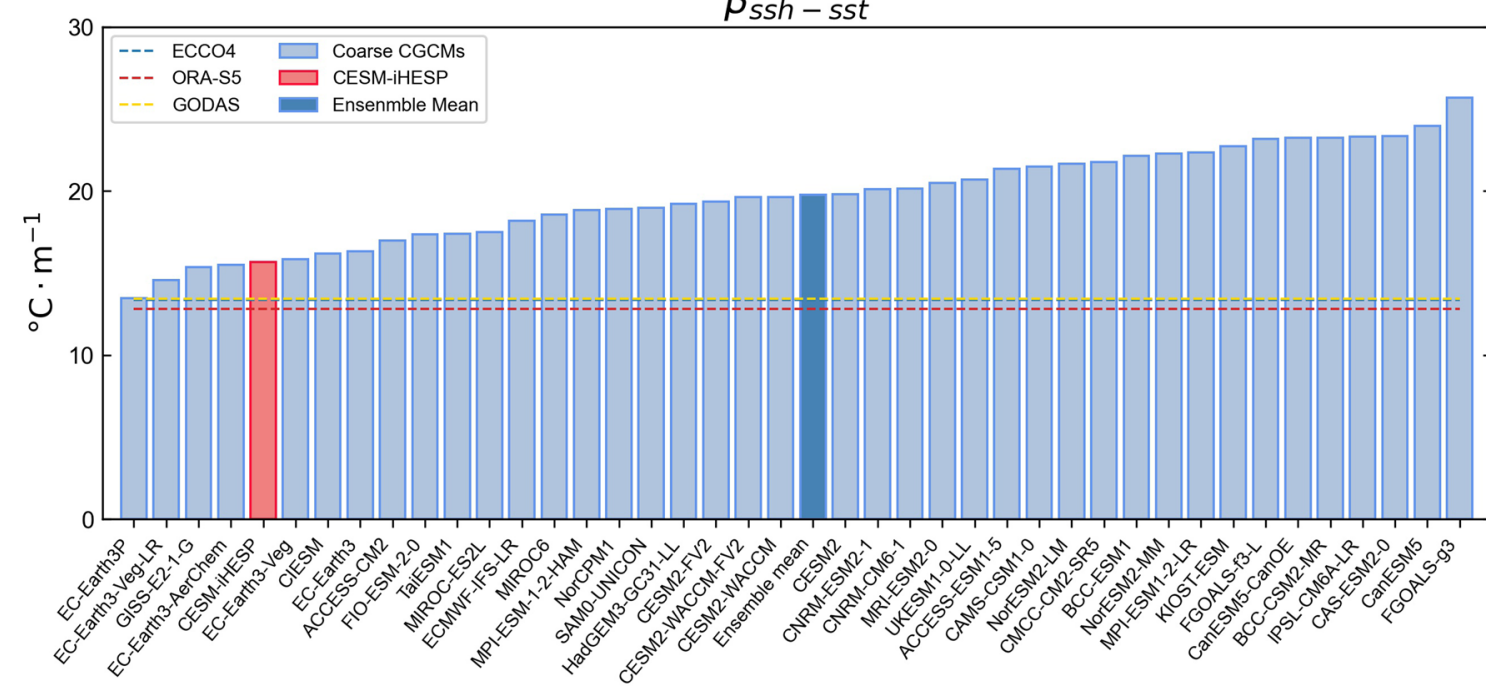

Extended Data Fig. 4 | See next page for caption. 


\section{NATURE GEOSCIENCE}

Extended Data Fig. 4 | Strength of Bjerknes feedback loop. Shown are three components in Bjerknes feedback loop in the CESM-iHESP (red bar), coarseresolution CGCMs (light blue bar) along with their ensemble mean (dark blue bar) and three reanalysis products (dashed lines). $\mathbf{a}$, Coupling between SST and zonal wind stress measured by the regression coefficient $\beta_{\text {sst-taux }}$ of zonal wind stress anomaly in the Niño 4 region onto SSTA in the Niño3 region, $\mathbf{b}$, coupling between zonal wind stress and thermocline measured by the regression coefficient $\beta_{\text {taux }- \text { ssh }}$ of sea surface height anomaly (SSHA) in the Niño3 region onto zonal wind stress anomaly in the Niño 4 region, and $\mathbf{c}$, coupling between thermocline and SST measured by the regression coefficient $\beta_{\text {ssh-sst }}$ of SSTA in the Niño3 region onto SSHA in the Niño3 region. A few coarse-resolution CGCMs listed in Extended Data Table 1, that is, CESM1-CAM5-SE-LR, GISS-E2-1-H, IITM-ESM, KACE-1-0-G and MCM-UA-1-0, are not included here due to the missing SSH data. Regression coefficients are calculated over 1950-2014 for all the CGCM simulations, but over the respective available periods for the reanalysis products. 
a

a

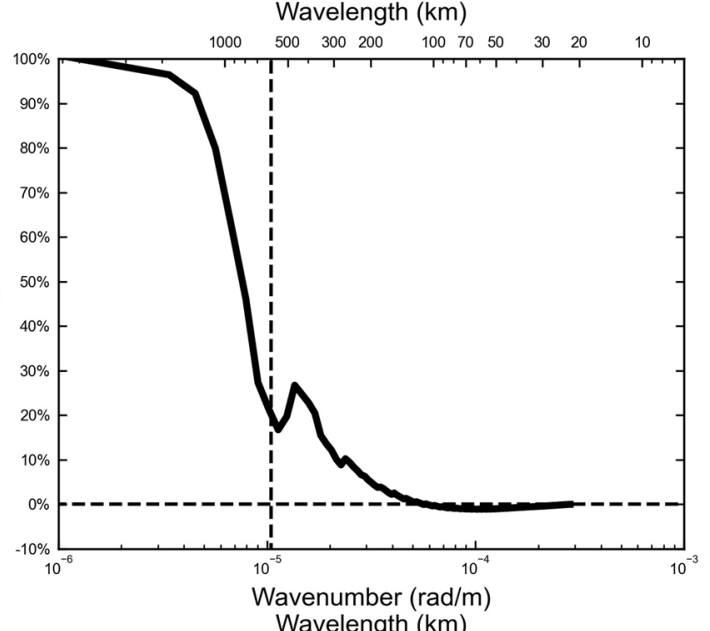

C

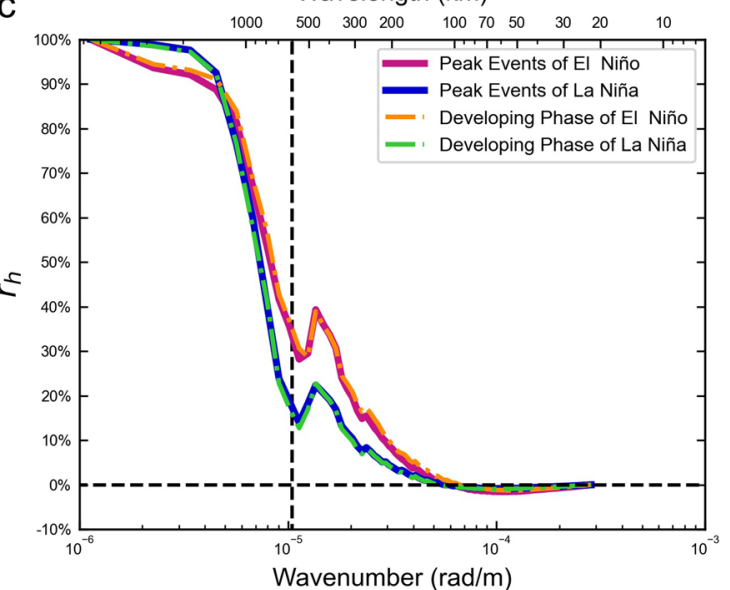

b

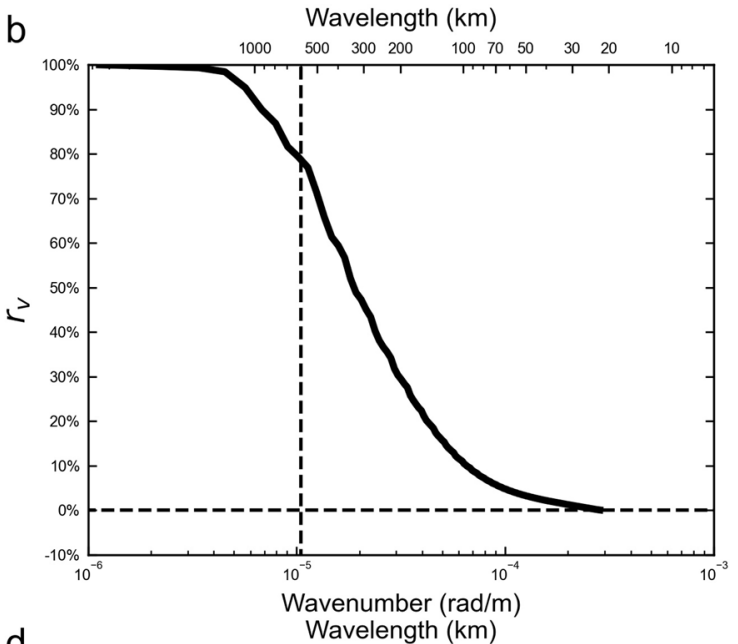

d

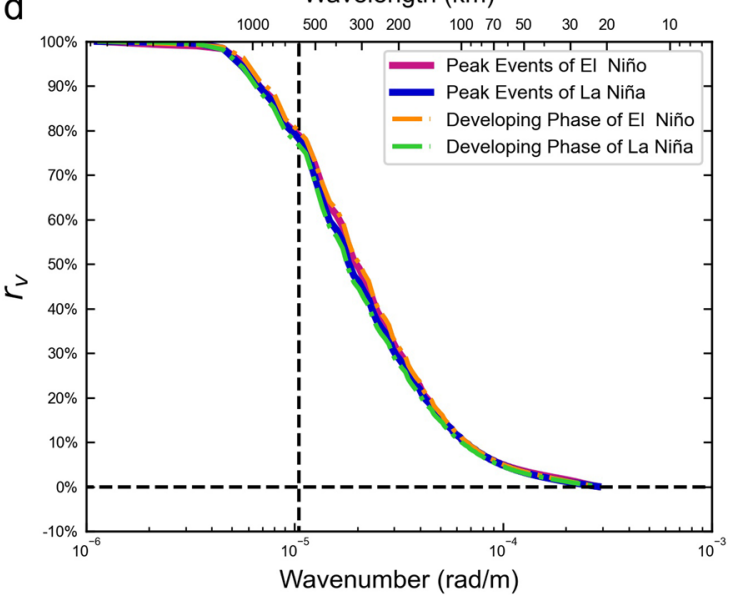

Extended Data Fig. 5 | Decomposition of Niño3.4 $Q_{\text {eddy,h }}$ and $Q_{e d d y, v}$ in the horizontal wavenumber space. Distribution of climatological mean $\mathbf{a}, r_{h}$ and $\mathbf{b}$, $r_{v}$ in the horizontal wavenumber space. $\mathbf{c}, \mathbf{d}$, Same as $\mathbf{a}, \mathbf{b}$, but for the composite of $r_{h}$ and $r_{v}$ during the peak El Niño/La Niña events and developing phase of El Niño/La Niña events. See 'Separating effects from mesoscale and submesoscale eddies' in Methods for the definitions of $r_{h}$ and $r_{v}$. 

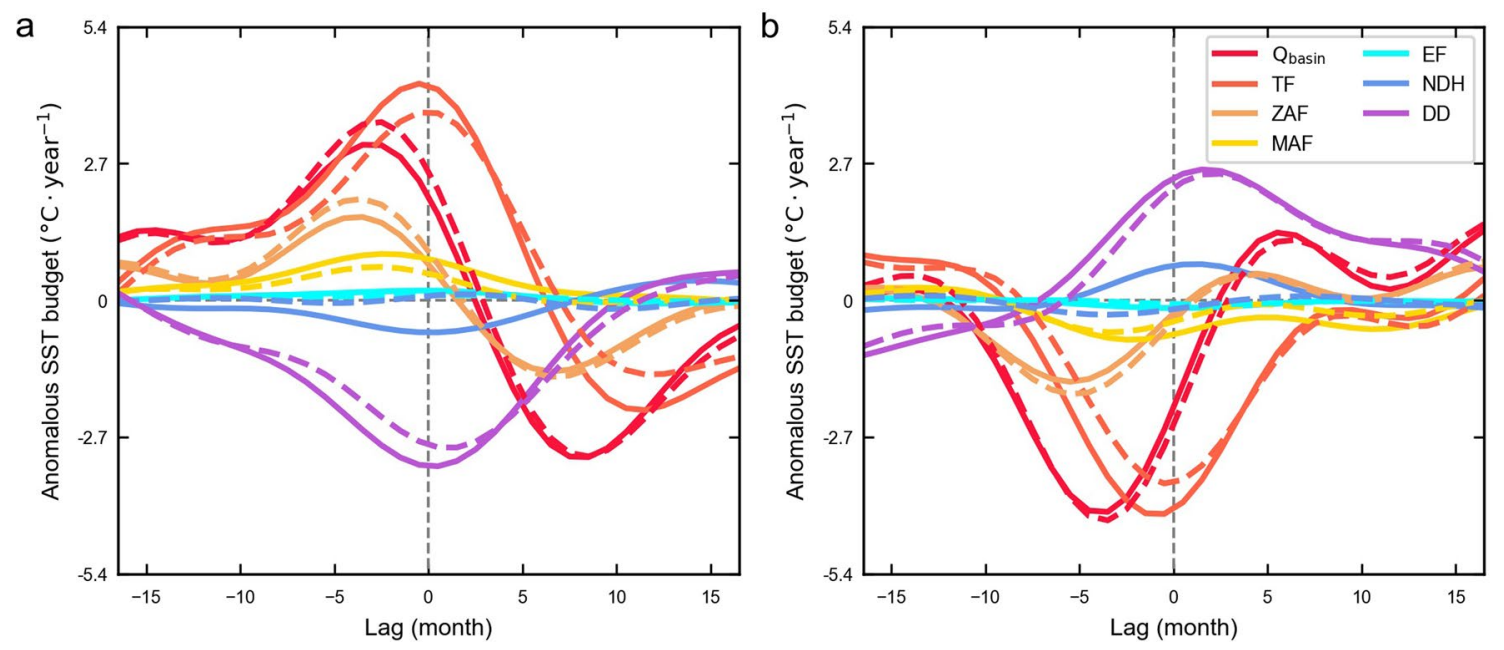

Extended Data Fig. 6 | Decomposition of $\boldsymbol{Q}_{\text {basin }}$ a, Decomposition of $Q_{\text {basin }}$ (solid line) in El Niño events into the thermocline feedback (TF), zonal advection feedback (ZAF), meridional advection feedback (MAF), Ekman feedback (EF), nonlinear dynamical heating (NDH), and dynamical damping (DD). The dashed lines correspond to the counterparts computed by removing the motions with horizontal wavelengths smaller than $1600 \mathrm{~km}$. $\mathbf{b}$, Same as a but for La Niña events. Negative (positive) lag months represent the ENSO developing (decaying) phase before (after) the peak of SSTA. 
a

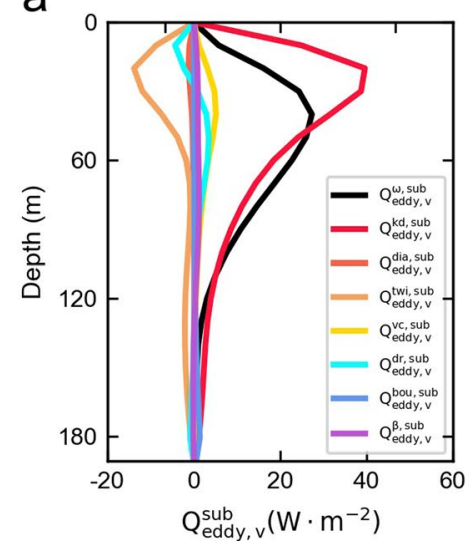

b

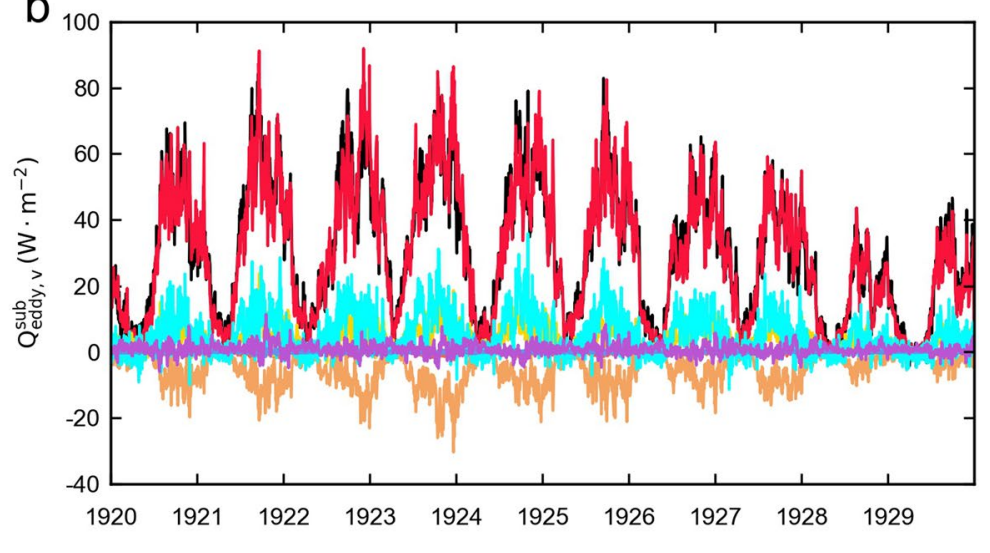

Extended Data Fig. 7 | Decomposition of $Q_{e d d y, v}^{\omega, \text { sub }}$ into different dynamical components. a, Vertical profiles of time-mean $Q_{e d d y, v}^{\omega, \text { sub }}$ averaged over the Niño3.4 region during 1920-1929 and its decomposition into different components. $\mathbf{b}$, Time series of $Q_{e d d y, v}^{\omega, s u b}$ at $50 \mathrm{~m}$ and its decomposition into different components at $50 \mathrm{~m}$ averaged over the Niño3.4 region. See 'Decomposing vertical submesoscale eddy heat flux into different ocean dynamics' in Methods for the meanings of labels. 


\section{NATURE GEOSCIENCE}
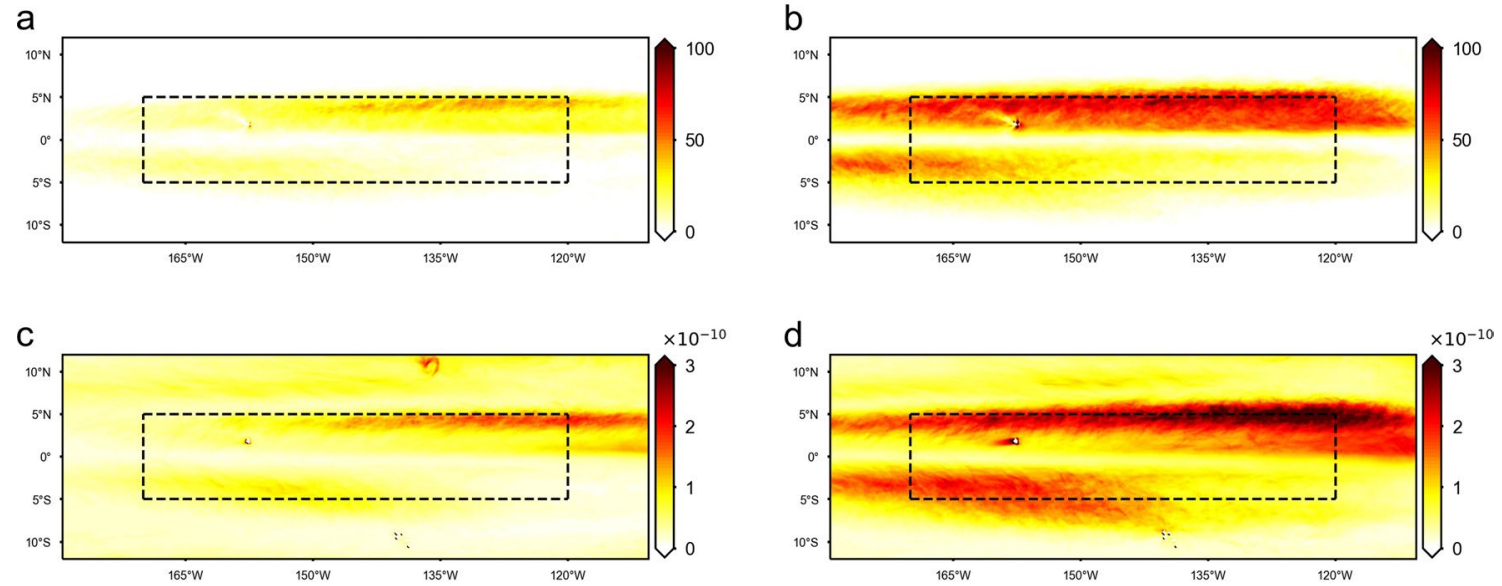

Extended Data Fig. 8 | Enhanced vertical submesoscale eddy heat flux in SST frontal regions. a, b, Spatial distribution of composite $Q_{e d d y, v}^{s u b}$ in $m^{-2}$ at $50 \mathrm{~m}$ during the peak El Niño and La Niña events, respectively. $\mathbf{c}, \mathbf{d}$, Same as $\mathbf{a}, \mathbf{b}$, but for squared horizontal SST gradient magnitude in ${ }^{\circ} \mathrm{C}^{2} \mathrm{~m}^{-2}$. 
Extended Data Table 1 | CGCMs used in this study. The coarse-, intermediate- and fine-resolution CGCMs are marked in blue, yellow and red, respectively. Length of simulation differs among CGCMs and their overlapping periods, 1950-2014, are adopted in this study

\begin{tabular}{|c|c|c|c|c|c|}
\hline CGCMs & $\begin{array}{l}\text { Oceanic } \\
\text { resolution }\end{array}$ & CGCMs & $\begin{array}{c}\text { Oceanic } \\
\text { resolution }\end{array}$ & CGCMs & $\begin{array}{l}\text { Oceanic } \\
\text { resolution }\end{array}$ \\
\hline ACCESS-CM2 & $1^{\circ}$ & EC-Earth3 & $1^{\circ}$ & SAM0-UNICON & $1^{\circ}$ \\
\hline ACCESS-ESM1-5 & $1^{\circ}$ & ECMWF-IFS-LR & $1^{\circ}$ & TaiESM1 & $1^{\circ}$ \\
\hline BCC-CSM2-MR & $1^{\circ}$ & FGOALS-f3-L & $1^{\circ}$ & UKESM1-0-LL & $1^{\circ}$ \\
\hline BCC-ESM1 & $1^{\circ}$ & FGOALS-g3 & $1^{\circ}$ & AWI-CM-1-1-HR & $0.25^{\circ}$ \\
\hline CAMS-CSM1-0 & $1^{\circ}$ & FIO-ESM-2-0 & $1^{\circ}$ & AWI-CM-1-1-MR & $0.25^{\circ}$ \\
\hline CAS-ESM2-0 & $1^{\circ}$ & GISS-E2-1-G & $1^{\circ}$ & $\mathrm{BCC}-\mathrm{CSM} 2 \mathrm{HR}$ & $0.25^{\circ}$ \\
\hline CESM1-CAM5-SE-LR & $1^{\circ}$ & GISS-E2-1-H & $1^{\circ}$ & $\mathrm{CMCC}-\mathrm{CM} 2-\mathrm{HR} 3$ & $0.25^{\circ}$ \\
\hline CESM2-FV2 & $1^{\circ}$ & HadGEM3-GC31-LL & $1^{\circ}$ & CMCC-CM2-VHR3 & $0.25^{\circ}$ \\
\hline CESM2-WACCM-FV2 & $1^{\circ}$ & IITM-ESM & $1^{\circ}$ & CNRM-CM6-1-HR & $0.25^{\circ}$ \\
\hline CESM2-WACCM & $1^{\circ}$ & IPSL-CM6A-LR & $1^{\circ}$ & EC-Earth3P-HR & $0.25^{\circ}$ \\
\hline CESM2 & $1^{\circ}$ & KACE-1-0-G & $1^{\circ}$ & ECMWF-IFS-HR & $0.25^{\circ}$ \\
\hline CIESM & $1^{\circ}$ & KIOST-ESM & $1^{\circ}$ & ECMWF-IFS-MRR & $0.25^{\circ}$ \\
\hline CMCC-CM2-SR5 & $1^{\circ}$ & MCM-UA-1-0 & $2.5^{\circ}$ & GFDL-CM4 & $0.25^{\circ}$ \\
\hline CNRM-CM6-1 & $1^{\circ}$ & MIROC-ES2L & $1^{\circ}$ & HadGEM3-GC31-HM & $0.25^{\circ}$ \\
\hline CNRM-ESM2-1 & $1^{\circ}$ & MIROC6 & $1^{\circ}$ & HadGEM3-GC31-MIV & $0.25^{\circ}$ \\
\hline CanESM5-CanOE & $1^{\circ}$ & MPI-ESM-1-2-HAM & $2.5^{\circ}$ & CESM1-CAM5-SE-HR & $0.1^{\circ}$ \\
\hline CanESM5 & $1^{\circ}$ & MPI-ESM1-2-LR & $2.5^{\circ}$ & FGOALS-f3-H & $0.1^{\circ}$ \\
\hline EC-Earth3-AerChem & $1^{\circ}$ & MRI-ESM2-0 & $1^{\circ}$ & HadGEM3-GC31-HH & $0.1^{\circ}$ \\
\hline EC-Earth3-Veg-LR & $1^{\circ}$ & NorCPM1 & $1^{\circ}$ & CESM-iHESP & $0.1^{\circ}$ \\
\hline EC-Earth3-Veg & $1^{\circ}$ & NorESM2-LM & $1^{\circ}$ & & \\
\hline EC-Earth3P & $1^{\circ}$ & NorESM2-MM & $1^{\circ}$ & & \\
\hline
\end{tabular}


Extended Data Table 2 | Inter-model correlation coefficients between the ENSO amplitude and strength of different components in Bjerknes feedback loop. Correlation coefficients statistically significant at the $99 \%$ confidence level are marked in bold. The meanings of $\beta_{\text {sst-taux }} \beta_{\text {taux-sshr }}$ and $\beta_{\text {ssh-sst }}$ are explained in the caption of Extended Data Fig. 4

\begin{tabular}{cccc}
\hline \hline & $\beta_{\text {sst-taux }}$ & $\beta_{\text {taux }- \text { ssh }}$ & $\beta_{\text {ssh-sst }}$ \\
\hline El Niño & 0.36 & $\mathbf{0 . 6 2}$ & 0.10 \\
La Niña & 0.01 & $\mathbf{0 . 6 9}$ & 0.36 \\
\hline
\end{tabular}

